FHWA/IN/JTRP-2006/33

Final Report

CRITICAL ROUTE NETWORK FOR EARTHQUAKE RESPONSE AND

DYNAMIC ROUTE ANALYSIS

Srinivas Peeta

Georgios Kalafatas

September 2007 


\section{TECHNICAL Summary}

INDOT Research

Technology Transfer and Project Implementation Information

TRB Subject Code: 12-3 State and Regional Studies

Publication No.FHWA/IN/JTRP-2006/33, SPR-3060

September 2007

Final Report

\section{Critical Route Network for Earthquake Response and Dynamic Route Analysis}

\section{Introduction}

In the JTRP-funded study "Emergency Earthquake Routes for the State of Indiana; Part I: Criteria for Selection of Primary Routes: Transportation Aspects," a multi-commodity maximal covering network design formulation based optimization methodology was proposed to identify a critical routes sub-network for the Indiana component of the Wabash Valley Seismic Zone in the INDOT Vincennes District. Addressed from a planning perspective, the primary objective was to strengthen the bridges on this sub-network through an effective seismic retrofit scheme so as to increase the likelihood of the critical routes being available to first responders following an earthquake to maximize response effectiveness. The proposed methodology was motivated by the need to consider the key factors for effective earthquake response in a single framework. This was done by first defining the concept of "critical routes." The critical routes of a transportation network are the set of routes whose functionality is critical to the effectiveness of earthquake response, or equivalently, the routes that provide the quickest response (least travel time) to most of the population (maximal coverage).
The above study considered all Interstates, US Roads and State Roads in identifying the critical routes sub-network that should be seismically strengthened. However, Part II of that study "Route Seismic Vulnerability Aspects," which addressed the bridge seismic retrofit aspects, considered only the sub-network corresponding to the National Highway System and the National Truck Network in identifying the bridges for retrofit. The current study seeks to analyze whether the sub-network corresponding to the National Highway System and the National Truck Network compares well, from a costsbenefits perspective, to that suggested by the previous study (Figure 6.1 of Part I Report). Hence, a key objective of the current study is from a planning perspective.

The second objective of the current study is in the operational context. It aims to determine a methodological framework for dynamically rerouting first responders when part of a route is unavailable due to the earthquake. This objective provides back-up operational response plans when specific road segments of the recommended critical routes sub-network fail during an actual earthquake.

\section{Findings}

In the context of the first objective, the study found that the performance of the subnetwork consisting of the National Highway System and the National Trucking Network is dominated by that of the more complete network used in the Part I Report of the previous study. This is illustrated by Figure 3.4 in the Draft Final Report of the current study. This is because the sub-network considered in the current study has lesser connectivity compared to the more complete network. That is, the more complete network offers better ways of connecting the major population centers with lesser cost.

The study also led to a few specific insights for decision-makers. The high capacity infrastructure associated with the National Highway System and the National Trucking Network can respond better under postearthquake high-volume scenarios associated with passenger and cargo movement in the medium- 
term. Also, its performance tends to increase when greater weight is provided to population coverage under the lower budget levels. However, as stated above, the more complete network based solution tends to dominate under low volume emergency response operations immediately after an earthquake; a wider range of routing options is available at lower retrofitting costs.

For the second objective, a methodological framework (operational flowchart Figure 4.1) was developed for dynamically updating the critical routes sub-network based on the surviving network after an earthquake. A software application was developed for implementing it for real-time operations. Before an earthquake, the network topology static database is maintained up to date, and represents the current network. Also, the network status dynamic database is initialized by specifying all links to be in unverified availability status. After an earthquake, the optimization component calculates the optimal routes considering the current network status. Then, the component responsible for verifying the availability status of the links used in the proposed routes will identify which links in the proposed routes have not been verified. If unverified links exist, they are made known to the decision-making agency. The agency is responsible for verifying the actual availability status of these links after the earthquake and then updating the network status dynamic database accordingly. After the dynamic database is updated, the new optimal critical routes sub-network is generated. The links in the updated sub-network with unverified availability status are verified by the agency. This procedure continues until the availability status of all links in the latest updated sub-network has been verified. Then, the optimal verified routes are made available.

\section{Implementation}

(1) The performance of the INDOT administered network (National Truck Network, National Highway System) is compared with that of the original critical routes network recommended in Part I of the SPR 2480 Final Report. This provides directions for choosing the final earthquake critical routes sub-network. (2) A dynamic rerouting methodological framework has been developed. A User Manual is provided for implementing it using the GAMS/CPLEX optimization software.

\section{Contacts}

For more information:

Prof. Srinivas Peeta

Principal Investigator

School of Civil Engineering

Purdue University

West Lafayette IN 47907

Phone: (765) 494-2209

Fax: (765) 496-7996

E-mail: peeta@ecn.purdue.edu

\author{
Indiana Department of Transportation \\ Division of Research \\ 1205 Montgomery Street \\ P.O. Box 2279 \\ West Lafayette, IN 47906 \\ Phone: (765) 463-1521 \\ Fax: (765) 497-1665
}

\section{Purdue University}

Joint Transportation Research Program

School of Civil Engineering

West Lafayette, IN 47907-1284

Phone: (765) 494-9310

Fax: (765) 496-7996

E-mail: jtrp@ecn.purdue.edu

http://www.purdue.edu/jtrp 
Final Report

FHWA/IN/JTRP-2006/33

\title{
CRITICAL ROUTE NETWORK FOR EARTHQUAKE RESPONSE AND DYNAMIC ROUTE ANALYSIS
}

\author{
By \\ Srinivas Peeta \\ Principal Investigator \\ Professor of Civil Engineering \\ and \\ Georgios Kalafatas \\ Graduate Research Assistant \\ School of Civil Engineering \\ Joint Research Transportation Program \\ Project No. C-36-56DDDD \\ File No. 7-4-81 \\ SPR-3060 \\ Prepared in cooperation with the \\ Indiana Department of Transportation and the \\ U.S. Department of Transportation \\ Federal Highway Administration
}

The contents of this report reflect the views of the authors who are responsible for the facts and the accuracy of the data presented herein. The contents do not necessarily reflect the official views or policies of the Indiana Department of Transportation or the Federal Highway Administration at the time of publication. This report does not constitute a standard, specification, or regulation.

Purdue University

West Lafayette, Indiana, 47907

September 2007 


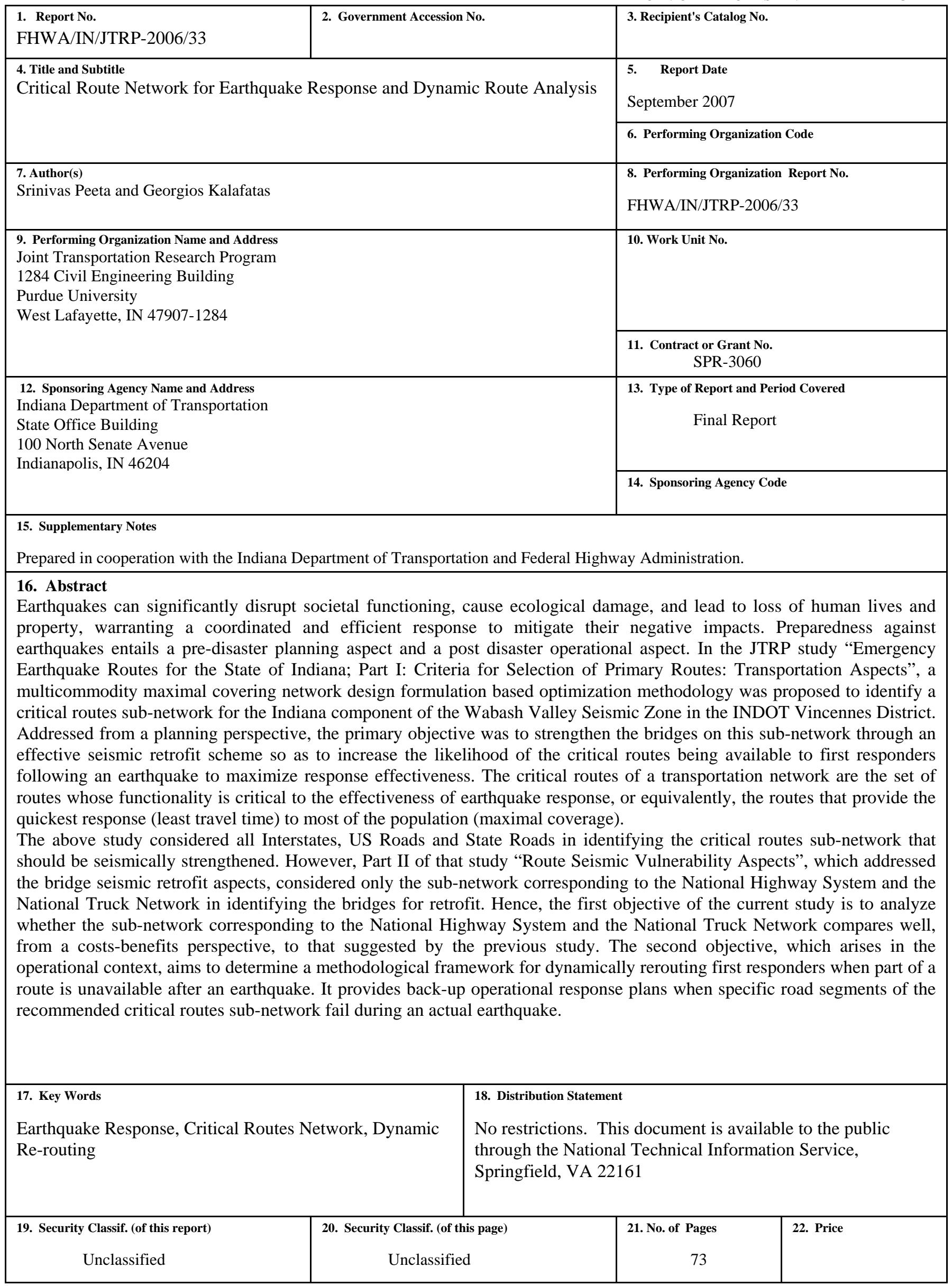




\section{ACKNOWLEDGMENTS}

The authors acknowledge the assistance and feedback from the members of the study advisory committee. The project was funded by the Joint Transportation Research Program of Purdue University in conjunction with the Indiana Department of Transportation and the Federal Highway Administration. We acknowledge and appreciate their support and assistance. 


\section{TABLE OF CONTENTS}

Page

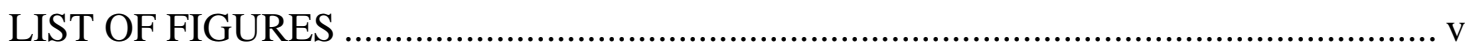

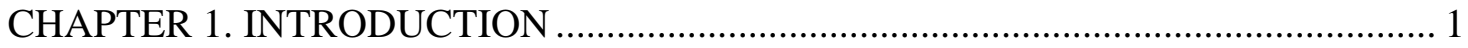

$1.1 \quad$ Background and motivation..................................................................... 1

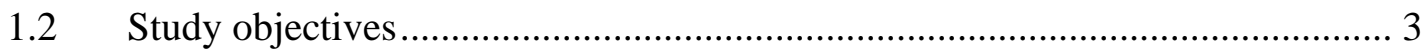

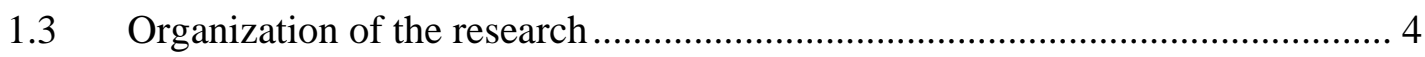

CHAPTER 2. AN IMPROVED FORMULATION FOR THE MCMCNDP..................... 8

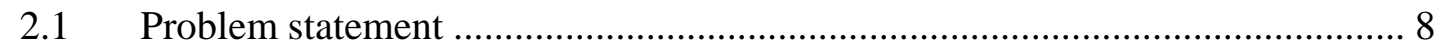

2.2 Key issues in the original formulation........................................................... 9

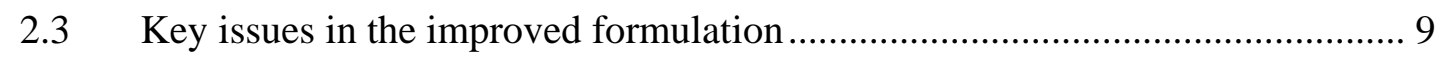

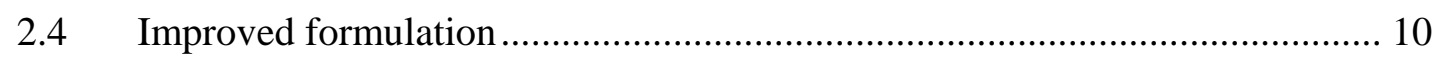

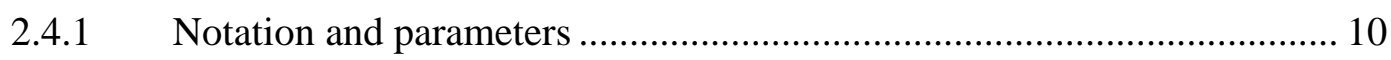

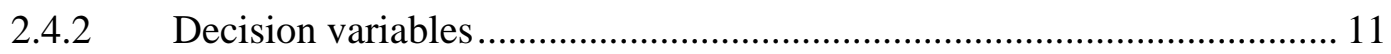

2.4.3 The MCMCNDP formulation ............................................................... 12

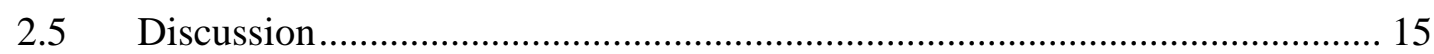

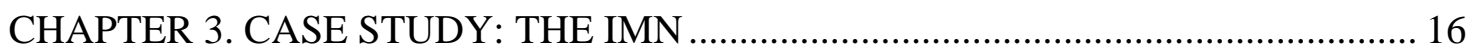

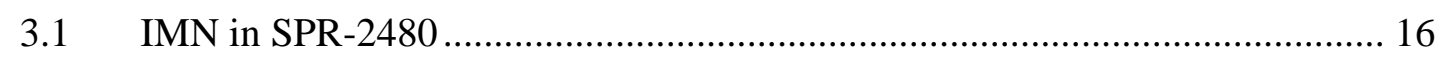

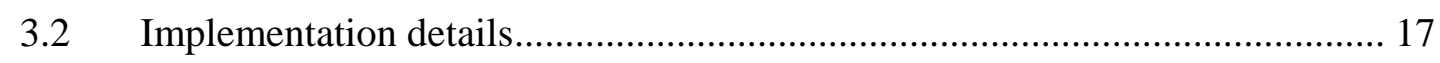

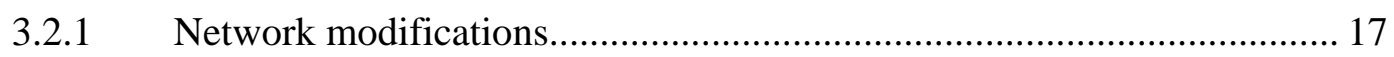

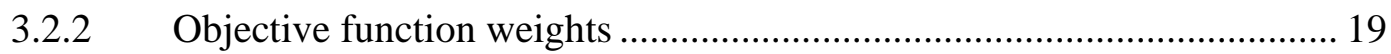


3.2.3 Bridge deck surface as a proxy for bridge seismic retrofit budget ........... 19

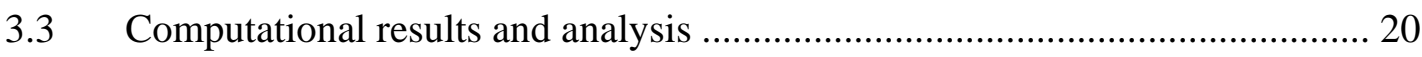

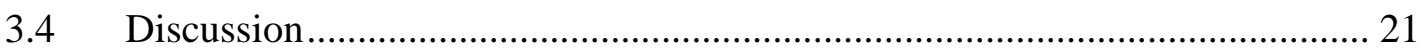

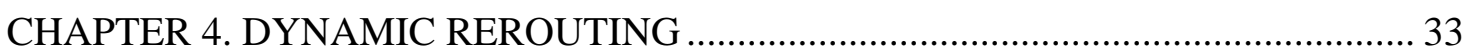

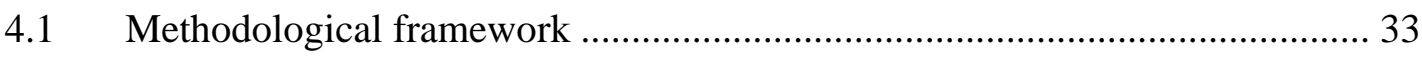

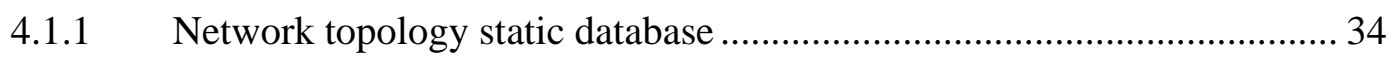

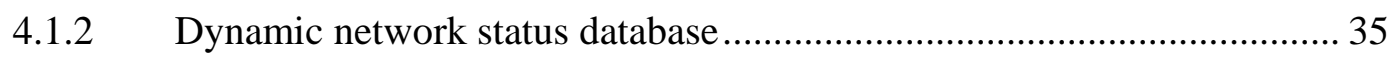

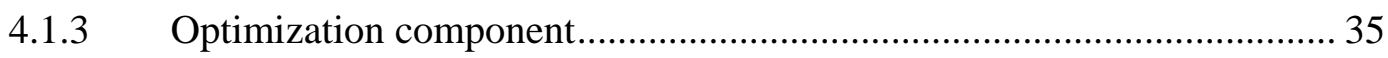

4.1.4 Proposed route verification component ................................................. 36

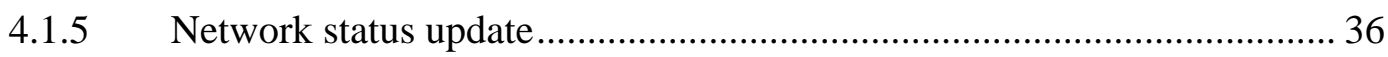

4.1.6 Verified optimal routes ............................................................................ 36

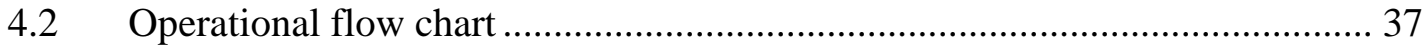

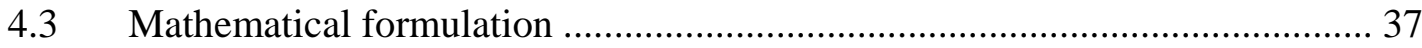

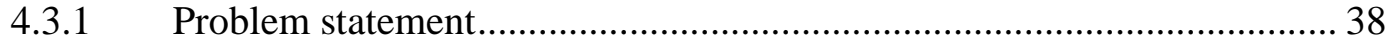

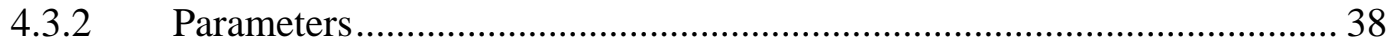

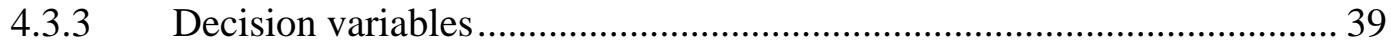

4.3.4 The dynamic rerouting formulation ......................................................... 39

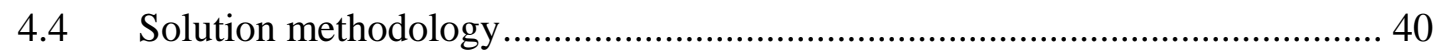

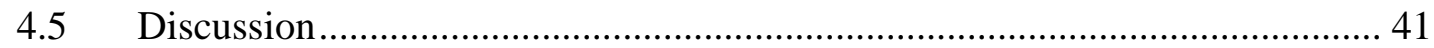

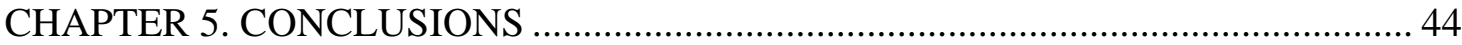

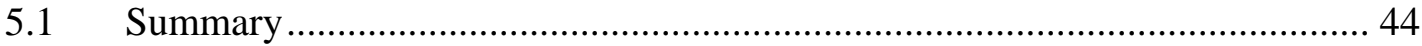

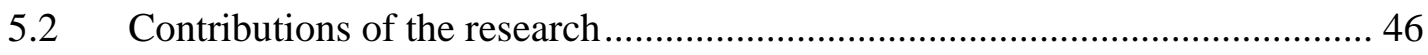

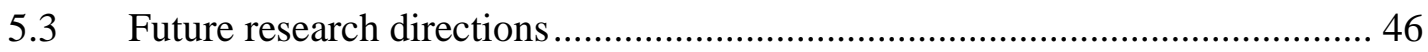

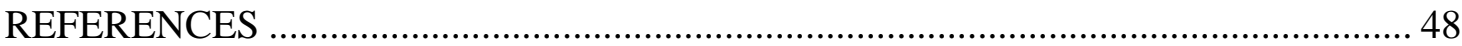

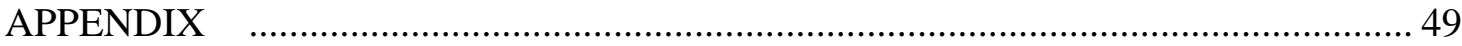

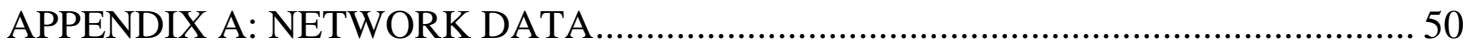




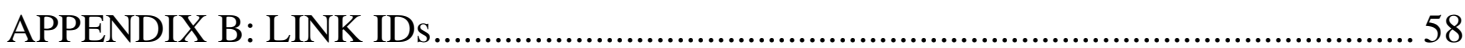

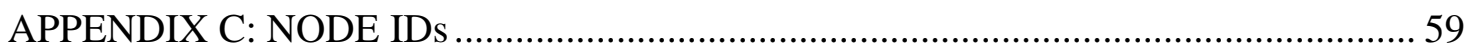

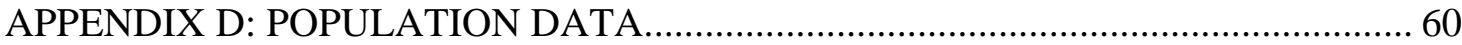

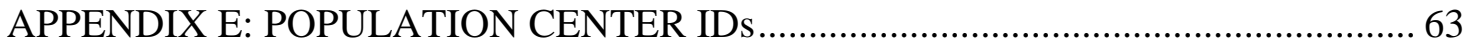

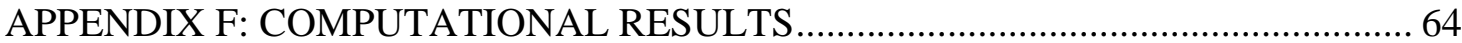

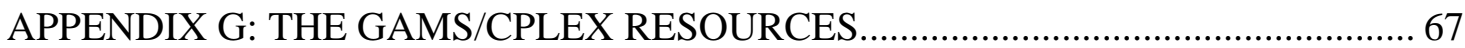

APPENDIX H: THE GAMS/CPLEX CODE FOR DYNAMIC REROUTING .............. 68

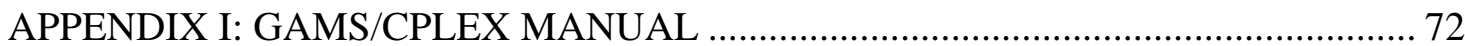




\section{LIST OF FIGURES}

Figure

Page

Figure 1.1. Suggested grid of the Earthquake Emergency Routes in the INDOT Vincennes District. 5

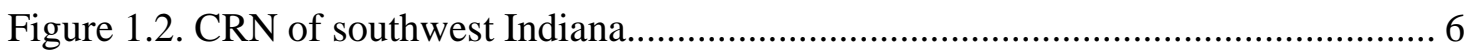

Figure 1.3. Non-inferior solution set for different budget values in the CRN................... 7

Figure 3.1. Two road segments of SR-37 existing in the IMN that are added to the CRN.

Figure 3.2. Modification of the northern border of the IMN (thick highlight). 23

Figure 3.3. The CRN (all links) and the IMN (highlighted links). 24

Figure 3.4. The set of non-inferior solutions for IMN and CRN 25

Figure 3.5. Percentage of the budget required for the CRN that belongs to the IMN...... 26 Figure 3.6. Critical routes for the weight pair $(0.999,0.001)$ and budget 1.67 million sq. feet in the IMN. 27

Figure 3.7. Critical routes for the weight pair $(0.990,0.010)$ and budget 2.00 million sq. feet in the IMN. 28

Figure 3.8. Critical routes for the weight pair $(0.999,0.001)$ and budget 2.00 million sq. feet in the IMN. 
Figure 3.9. Critical routes for the weight pair $(0.990,0.010)$ and budget 2.33 million sq. feet in the IMN Figure 3.10. Critical routes for the weight pair $(0.983,0.017)$ and budget 2.63 million sq.

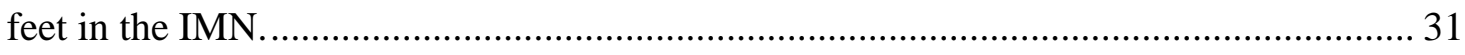
Figure 3.11. Critical routes for the weight pair $(0.995,0.005)$ and budget 3.33 million sq. feet in the IMN Figure 4.1. Operational flow chart for the calculation of the optimal dynamic routes..... 43 


\section{CHAPTER 1. INTRODUCTION}

\subsection{Background and motivation}

Earthquakes can significantly disrupt societal functioning, cause ecological damage, and lead to loss of human lives and property, warranting a coordinated and efficient response to mitigate their negative impacts (Peeta and Viswanath, 2004). Past experience with earthquakes has demonstrated the vulnerability of the critical infrastructural lifelines and the need for mitigation strategies as well as emergency response planning. Preparedness against earthquakes includes a pre-disaster planning aspect and a post disaster operational aspect.

In the INDOT-funded study "Emergency Earthquake Routes for the State of Indiana; Part I: Criteria for Selection of Primary Routes: Transportation Aspects” (SPR2480), Peeta and Viswanath (2004) developed a methodology to address the problem from a planning perspective. It enabled the decision-makers to identify an effective seismic retrofit scheme vis-à-vis earthquake response for the bridges of a network. The methodology was motivated by the need to consider the key factors for effective earthquake response in a single framework. This was done by first defining the concept of critical routes. The critical routes of a transportation network are the set of routes whose functionality is critical to the effectiveness of earthquake response, or 
equivalently, the routes that provide the quickest response (least travel time) to most of the population (maximal coverage) among all major population centers.

The critical routes problem in the previous INDOT study led to a network approach with multiple origin-destination (O-D) pairs, labeled the Multi Commodity Maximal Covering Network Design Problem (MCMCNDP). Its objectives are to minimize the routing costs over all O-D pairs and maximize the total population covered, subject to a budget constraint based on the fixed costs incurred on the chosen links. As mentioned earlier, the MCMCNDP represents the planning aspect of identifying the bridges to seismically retrofit by factoring the transportation performance aspects in determining the critical routes.

In an operational context following an earthquake, first responders seek to reach the affected population in the least time possible. This problem is classified as a multicommodity uncapacitated shortest path problem, which is decomposed to multiple single shortest paths. Extensive literature exists on solution algorithms for the shortest path problem (Ahuja et al., 1993). Nevertheless, the key issue is that the status of the network, in terms of whether a link is accessible or inaccessible due to severe seismic damage, is unknown.

The unknown state of the network in the aftermath of an earthquake generates two major problems. First, the feasibility of a proposed route is not guaranteed since it may contain inaccessible links leading to delays in first response operations. Second, the time to acquire the information on the status of the entire network is critical for on-time deployment; this can be a time consuming task. Interestingly, it is not necessary that the 
status of every link in the network has to be known. If just the sub-network that provides the shortest paths is examined, then the quickest feasible deployment of first responders can be achieved.

\subsection{Study objectives}

This study has two objectives. The first objective has a planning perspective while the second objective has an operational perspective.

The first objective is to analyze the performance of the network shown in Figure 4.5 of Part II of SPR-2480 Final Report (shown in Figure 1.1 of this report) in terms of earthquake response planning, compared to the performance of the network shown in Figure 6.1 of Part I of SPR-2480 Final Report (shown as Figure 1.2 here).

Currently, the difference between the route networks shown in Figures 1.1 and 1.2 is that the former network corresponds to routes that belong to the National Truck Network and the National Highway System, and are maintained by the Indiana Department of Transportation, hereafter called the INDOT-Maintained Network (IMN). The latter considers all Interstates, US Roads and State Roads in the vicinity of Vincennes District of southwest Indiana, hereafter called the Complete Road Network (CRN). The IMN is a sub-network of the CRN.

In the INDOT-funded project SPR-2480, the MCMCNDP had been applied to the CRN. However, the CRN includes road segments which are maintained either by INDOT or by other local authorities. In this study, the MCMCNDP will be applied to the IMN so as to compare its performance to that of the CRN. 
The results will be analyzed using the format of Figure 6.1 of SPR-2480 (indicated as Figure 1.3 here), which shows the non-inferior solution fronts. A noninferior solution front is the curve of those solutions for which the best performance level of the second objective (maximum population coverage) is achieved (as shown in Figure 1.3) for a given performance level of the first objective (least travel time).

The second objective is to determine a methodological framework to dynamically reroute first responders when part of a route is unavailable due to the earthquake. This objective provides back-up operational response actions when specific road segments of the recommended primary route network fail during an actual earthquake.

\subsection{Organization of the research}

The remainder of the research is organized as follows. Chapter 2 provides an improved formulation for the MCMCNDP. Chapter 3 identifies the IMN where the MCMCNDP will be applied, and compares the computational results to the computational results of the CRN in southwest Indiana (Peeta, Viswanath, 2004). In Chapter 4 the problem of dynamic rerouting of first responders from their bases to the affected population centers is defined. The methodological framework is analyzed, the corresponding formulation is provided and a computationally efficient solution methodology is developed. Chapter 5 summarizes the research and its contributions, and provides future research directions. 


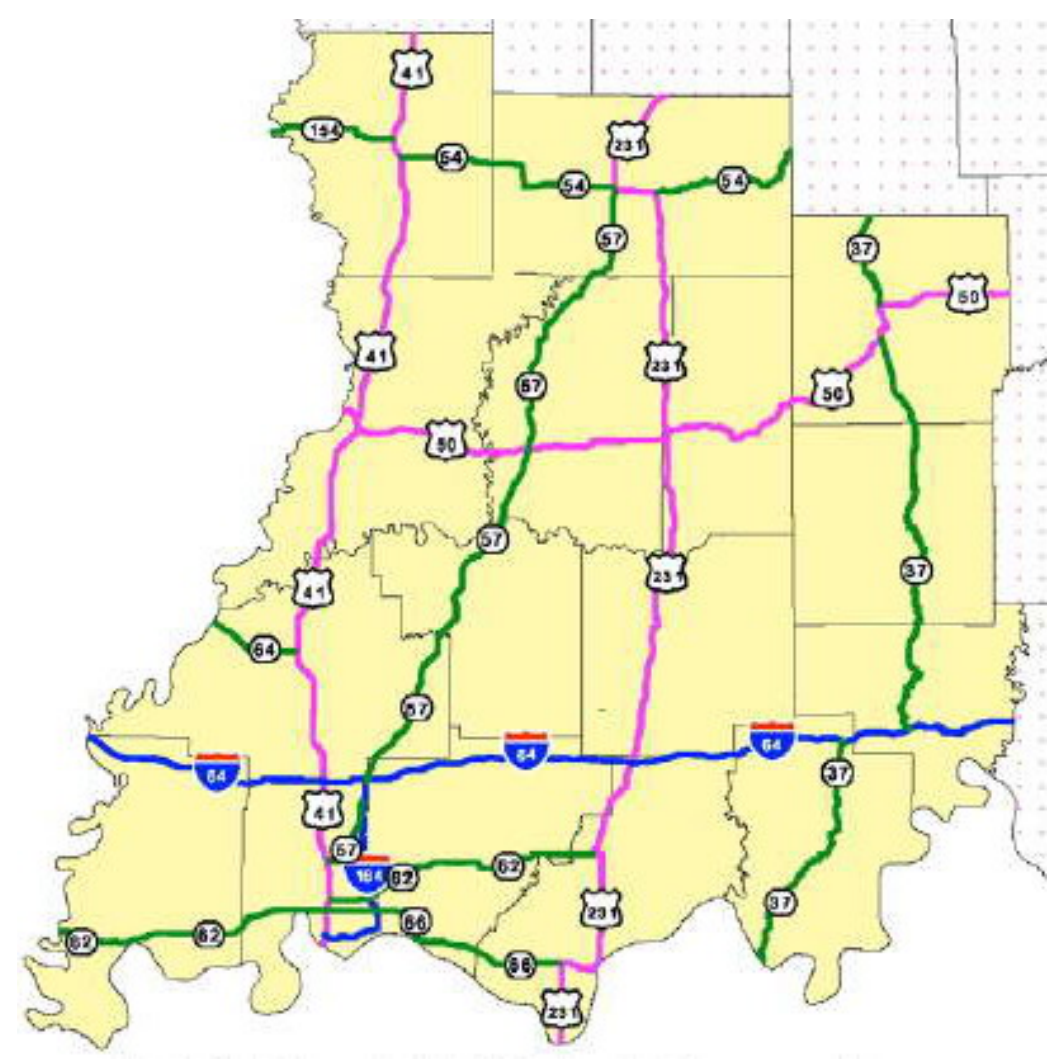

Figure 1.1. Suggested grid of the Earthquake Emergency Routes in the INDOT Vincennes District. 


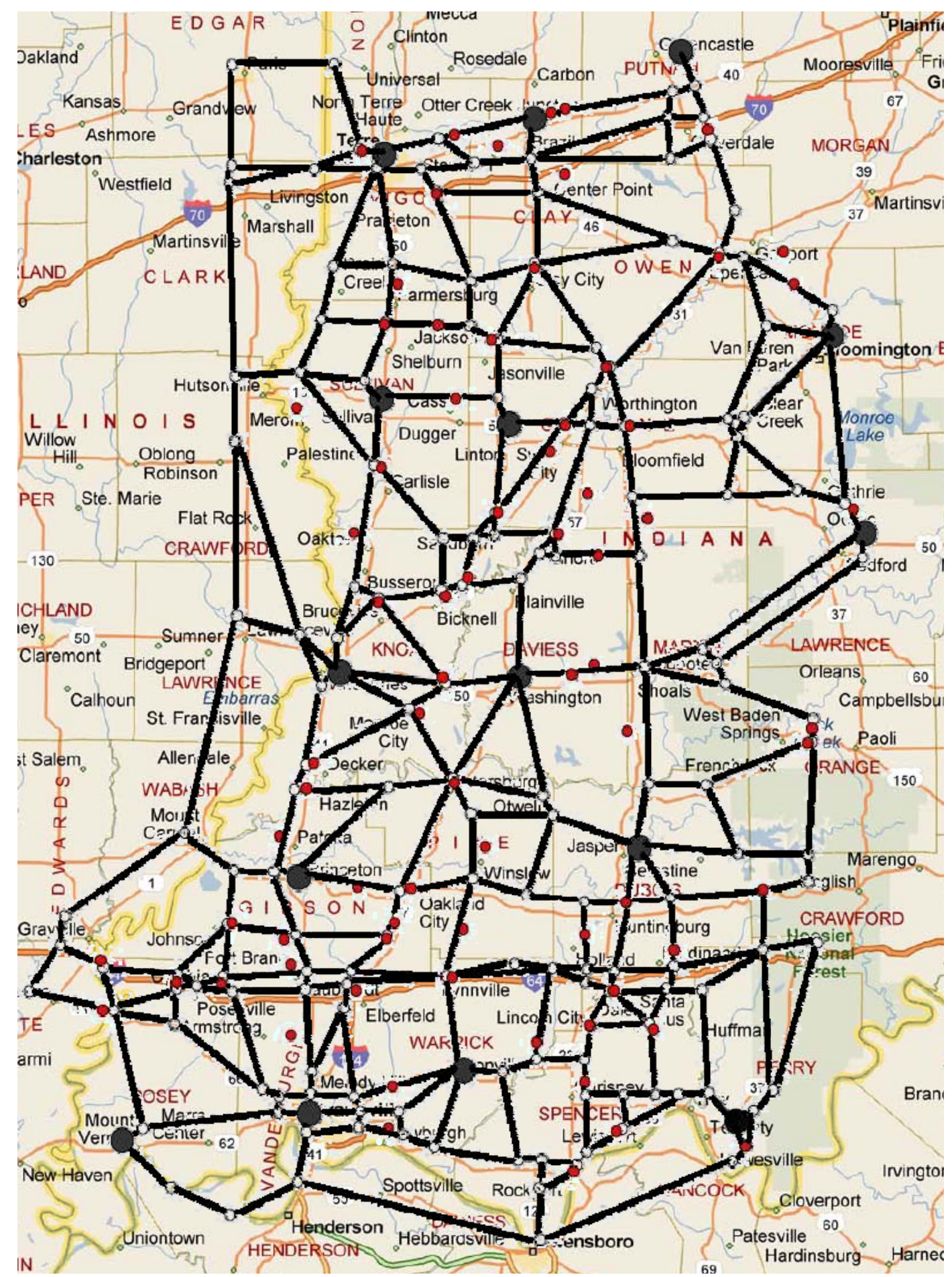

Figure 1.2. CRN of southwest Indiana. 


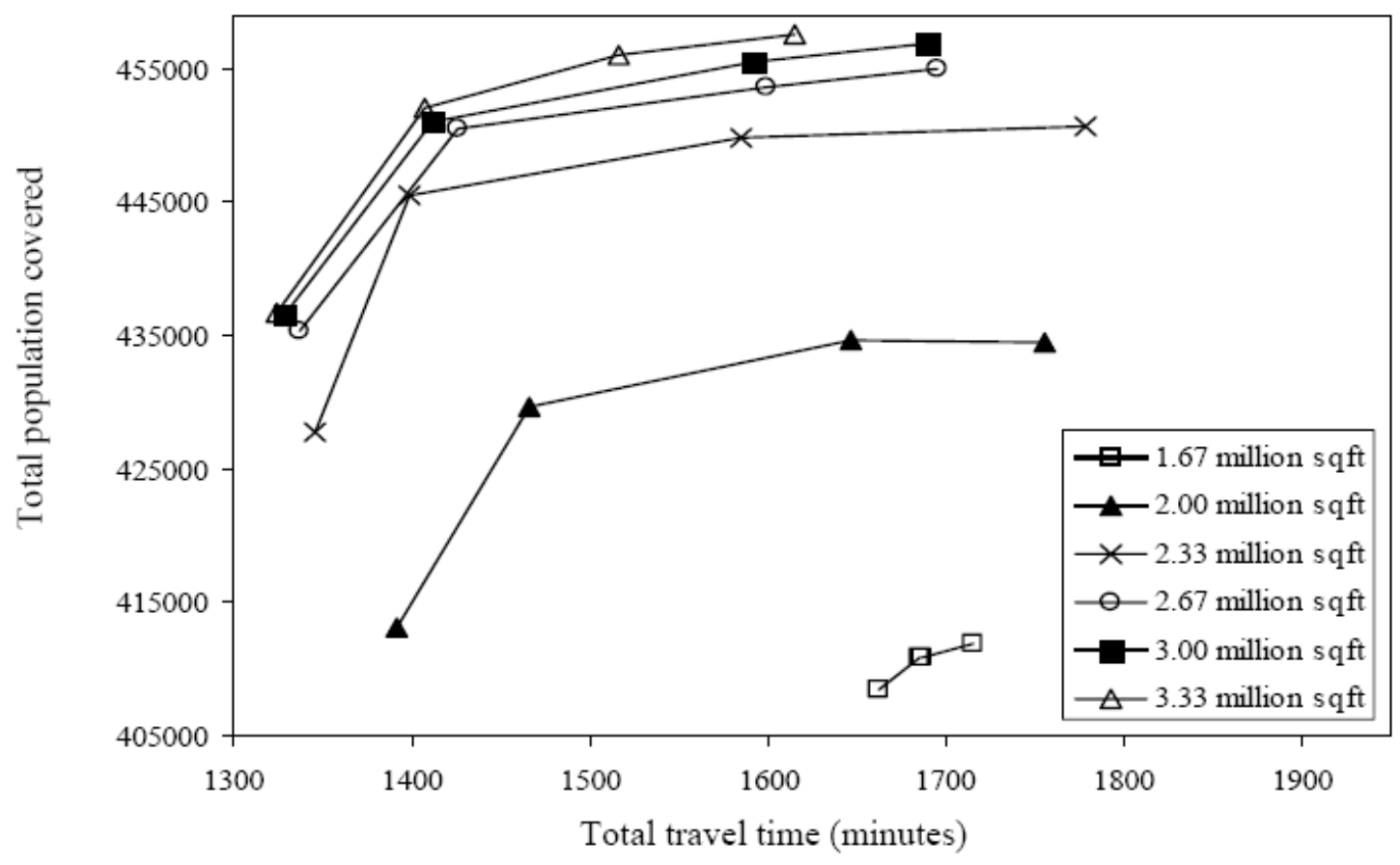

Figure 1.3. Non-inferior solution set for different budget values in the CRN. 


\section{CHAPTER 2. AN IMPROVED FORMULATION FOR THE MCMCNDP}

This chapter introduces an improved formulation for the MCMCNDP. Section 2.1 states the MCMCNDP. Section 2.2 addresses the key issues of the original formulation that increase the complexity of the formulation. Section 2.3 discusses how those issues are addressed in the improved formulation. Section 2.4 introduces the improved mathematical formulation. Section 2.5 summarizes the improved mathematical formulation.

\subsection{Problem statement}

The MCMCNDP is defined hereby. We are given the locations of demand population centers of a region and its associated undirected network. The network links have a fixed budgetary cost for their usage (bridge retrofitting) and a routing cost (travel time). There is a budget constraint on the total budgetary cost incurred. The MCMCNDP seeks to allocate a limited budget to retrofit links such that the total routing costs for a set of O-D pairs is minimized and the total demand covered by the routes connecting them is maximized. The demand of a center is covered if a link in one of the selected routes provides access to it. 


\subsection{Key issues in the original formulation}

The original formulation had been an NP-hard integer formulation. Due to the intractable nature of the sub-tour elimination constraints, a significant part of the expected isolated sub-tours was handled by the valid inequalities and the rest of them were manually removed. This lead to increased computational time due to a) manual or exogenous interference with another software, b) additional computations for each of the new exogenously identified sub-tours, till all sub-tours were eliminated. Finally, in the original formulation the set of variables handling a) the decision to retrofit a link and b) the population demand coverage, were binary and not linear. This increased the size of the branch-and-bound tree, thus affecting significantly the computational time.

\subsection{Key issues in the improved formulation}

In the proposed improved formulation, all tours are handled in a single compact formulation. The concept utilized to handle all sub-tours in the improved formulation is an extension of Wong (1980) sub-tour elimination technique used for the traveling salesman problem. The difference is that in the traveling salesman problem all nodes have to be connected in a single tour, while in the coverage problem not all nodes have to be in the "covering” path. A special variable identifying the existence of a node in a path is introduced along with the corresponding constraints. The mechanism is as follows. If an isolated tour exists then a set of nodes belonging to the tour is defined. For these nodes, an auxiliary flow, which is not allowed in unused paths of the main routing flow, can never be sent from the origin to the nodes of the isolated sub-tour, thus allowing no isolated-tour to exist. 
Moreover, the integrality constraint for the set of variables handling a) the decision to retrofit a link and b) the population demand coverage, are linearly relaxed. The set of variables handling the decision to retrofit a link has a lower bound defined by the existence of commodity flow and an upper bound defined by the budget constraint. The set of variables handling the population demand coverage is bounded by unity since a population considered will be covered be covered at most once.

The hereafter improved formulation addressed all sub-tours in a single computation step and it is a mixed integer formulation with a reduced number of binary variables.

\subsection{Improved formulation}

This section first describes the notation, parameters and decision variables, and then introduces the mixed integer programming formulation for the MCMCNDP.

\subsubsection{Notation and parameters}

Let $G(N, E)$ denote an undirected network with node set $N$ and link set $E$. The indices $i$ and $j$ denote a node in the network, $i, j \in N$ and $E \subseteq N \times N$, where $[i, j]$ denotes an undirected link between nodes $i$ and $j$ with a nonnegative fixed cost $f_{i j}$. Let $B$ to denote the available budget. Each O-D pair in the network is represented as a unique commodity type. Let $k$ represent the commodity type index, $k \in K$, where $K$ denotes the set of all commodities. One unit of flow of commodity $k$ must be transported over the network from its origin $O(k)$ to its destination $D(k)$. To differentiate the 
direction of flow of a commodity, we consider two directed links $(i, j)$ and $(j, i)$ corresponding to each original undirected link $[i, j]$. Let $A$ denote the set of the directed links; all links are uncapacitated. Parameter $b_{i}^{k}$ denotes whether node $i$ is an origin, a destination or intermediate node for commodity $k$. If node $i$ is an origin for commodity $k$ then $b_{i}^{k}=-1$. If node $i$ is a destination for commodity $k$ then $b_{i}^{k}=1$. If node $i$ is an intermediate node for commodity $k$ then $b_{i}^{k}=0$.

Let $c_{i j}^{k}$ be the nonnegative routing cost for a unit of commodity $k$ on link $(i, j)$, and $m$ the demand center index, $m \in M$, the set of demand centers in the region. Let $r_{m}$ represent the demand associated with demand center $m$, and $E_{m}$ the set of links that are eligible to cover it. The demand centers are treated separately from the nodes in the network, whereas past studies assign demand centers to a node in the network which is a more restrictive approach. Finally, the two objectives of total travel time and coverage, are including in a single weighted objective after being multiplied with weights $u_{1}$ and $u_{2}$ respectively.

\subsubsection{Decision variables}

The formulation contains five types of variables.

(i) The arc flow variables denoted by the vector $x=\left\{x_{i j}^{k}\right\}$, which define the flow of different commodities in each of the selected links. If there is a unit flow of commodity $k$ on link $(i, j)$ then $x_{i j}^{k}=1$, otherwise $x_{i j}^{k}=0$. 
(ii) The design variables denoted by the vector $y=\left\{y_{i j}\right\}$, which define the links selected for the network design. If link $[i, j]$ is used in a flow path then $y_{i j}=1$, otherwise $y_{i j}=0$. In the improved formulation this set of variables is linearly relaxed because at optimality conditions it is either 0 or 1 strictly.

(iii) The coverage variables denoted by the vector $z=\left\{z_{m}\right\}$, which define whether or not a demand center is covered. If demand center $m$ is accessible from a link of a flow path then $z_{m}=1$, otherwise $z_{m}=0$. In the improved formulation this variable is also linearly relaxed because at optimality conditions it is either 0 or 1 strictly.

(iv) The variables denoted by $v=\left\{v_{i}^{k}\right\}$, which define the number of times that a node is crossed from a path per commodity. They are modeled as linear variables because they are defined directly from the integral flow variables.

(v) The auxiliary flow variables denoted by the vector $w=\left\{w_{i j}^{k}\right\}$, which indicate the auxiliary flow routed to ensure connectivity among all nodes used in the path of commodity $k$, therefore ensuring that no isolated sub-tours exist. Those variables are also linear because they are only needed to establish connectivity.

\subsubsection{The MCMCNDP formulation}

The MCMCNDP formulation has two objectives: $Z_{1}$, the total routing cost and $Z_{2}$ the total demand covered, where, 


$$
Z_{1}=\sum_{k \in K} \sum_{(i, j) \in E} c_{i j}^{k} \cdot x_{i j}^{k} \quad \text { and } \quad Z_{2}=\sum_{m \in M} r_{m} \cdot z_{m}
$$

The mixed integer programming formulation for the MCMCNDP is expressed as follows:

Minimize: $\quad u_{1} Z_{1}-u_{2} Z_{2}$

Subject to:

$$
\begin{array}{lr}
\sum_{(i, j) \in A} x_{i j}^{k}-\sum_{(j, i) \in A} x_{j i}^{k}=b_{i}^{k} & \forall i \in N, \forall k \in K \\
z_{m} \leq \sum_{k \in K} \sum_{[i, j] \in E_{m}}\left(x_{i j}^{k}+x_{j i}^{k}\right) & \forall m \in M \\
x_{i j}^{k} \leq y_{i j} & \forall k \in K, \forall[i, j] \in E \\
x_{j i}^{k} \leq y_{i j} & \forall k \in K, \forall[i, j] \in E \\
\sum_{[i, j] \in E} f_{i j} \cdot y_{i j} \leq B & \forall i \in N, \forall k \in K \\
v_{i}^{k}=\frac{1}{2}\left(\sum_{(i, j) \in A} x_{i j}^{k}+\sum_{(j, i) \in A} x_{j i}^{k}+\left|b_{i}^{k}\right|\right) & \forall i \in N, \forall k \in K \\
v_{i}^{k} \leq 1 & \forall i \in N, b_{i}^{k}=0, \forall k \in K \\
\sum_{(i, j) \in A} w_{i j}^{k}-\sum_{(j, i) \in A} w_{j i}^{k}=v_{i}^{k} & \forall i \in N, b_{i}^{k}=-1, \forall k \in K \\
\sum_{(i, j) \in A} w_{i j}^{k}-\sum_{(j, i) \in A} w_{j i}^{k}=-\sum_{i \in N, b_{i}^{k}=0} v_{i}^{k} & \forall k \in K, \forall[i, j] \in E \\
w_{i j}^{k} \leq(|N|-2) \cdot x_{i j}^{k} & \forall k \in K, \forall[i, j] \in E \\
y_{i j}^{k} \leq 1 & \forall m \in M \\
z_{m} \leq 1 & \\
& \\
& \\
& \\
& \\
&
\end{array}
$$




$$
\begin{array}{lr}
y_{i j}^{k}, w_{i j}^{k} \geq 0 & \forall k \in K, \forall[i, j] \in E \\
z_{m} \geq 0 & \forall m \in M \\
v_{i}^{k} \geq 0 & \forall i \in N, \forall k \in K \\
x_{i j}^{k} \in\{0,1\} & \forall k \in K, \forall[i, j] \in E
\end{array}
$$

Constraint (2.2) is the conservation of flow for all commodities and nodes. Constraint (2.3) allows a population center to be covered only if there is a commodity flow in the adjacent links. Constraint (2.4) and (2.5) do not allow routing in a link, unless it has been retrofitted. Constraint (2.6) is the total budget constraint.

The new constraints added for handling the isolated sub-tours are constraints (2.7)-(2.11). Constraint (2.7) defines how many times a node is crossed in the path of a commodity, and constraint (2.8) ensures that this node is crossed at most once per commodity. This constraint ensures that sub-tours attached to the main path do not exist. Constraint (2.9) makes each crossed node a destination node for the auxiliary flow ensuring connectivity (therefore eliminating sub-tours) and constraint (2.10) indicates the total amount of auxiliary flow sent from the origin of each node to all other intermediate nodes for ensuring the conservation of the auxiliary flow. Constraint (2.11) restricts auxiliary flow only to the links that the main flow (response vehicles) has been routed.

Constraints (2.12) and (2.13) are the upper linear bound of the previously binary variables. Constraints (2.14) to (2.16) are the non-negativity constraints for the linear variables and constraint (2.17) is the integrality constraint for the flow variables. 


\subsection{Discussion}

In this chapter the MCMCNDP was stated. Key issues of the original formulation were identified considering the set of sub-tour elimination constraints and the number of integer variables. The improved formulation for the MCMCNDP addresses these issues by a) directly eliminating all sub-tours in a single computation step, and b) reducing the number of binary variables by applying the appropriate linear relaxations. The improved formulation is used for the IMN. 


\section{CHAPTER 3. CASE STUDY: THE IMN}

Chapter 3 studies the IMN. This chapter discusses the application of the MCMCNDP formulation to the determination of critical routes for earthquake response in southwest Indiana. It describes the details of the case study, followed by a summary of the solution procedure and its implementation. In Section 3.1 the IMN is described. In Section 3.2 implementation details for both the CRN and IMN are discussed. In Section 3.3 the computational results are presented. A concluding discussion is provided in Section 3.4.

\section{1 $\underline{I M N}$ in $S P R-2480$}

The IMN in SPR-2480 consists of the following road segments, as shown in Figure 1.1:

- US-41 from Terre Haute south to Evansville and the Kentucky border (Ohio River).

- SR-67 from Freedom to SR-57 junction and SR-57 from SR-67 to I-64.

- I-164 from I-64 to US-41.

- US-231 from SR-54 at Bloomfield south to Rockport and to Kentucky border (Ohio River). 
- $\quad$ SR-37 from Bloomington south to SR-237 and SR-237 to Cannelton and the Kentucky border (Ohio River).

- SR-154 from Illinois border (Wabash River) to US-41, and SR-54 from US-41 east to SR-45.

- US-50 from Illinois border (Wabash River) at Vincennes east to SR-446 east of Bedford.

- SR-64 from Illinois border (Wabash River) to Princeton to US-41.

- I-64 from Illinois border (Wabash River) to SR-66 at Carefree.

- SR-57 from US-41 past Evansville Airport to I-164.

- $\quad$ SR-62 from Illinois border (Wabash River) through Evansville to US-231.

- SR-66 from US-41 east to Rockport.

\subsection{Implementation details}

The implementation details refer to: (i) modifications to the IMN and the CRN (Section 3.2.1), (ii) the numerical selection of the objective function weights (Section 3.2.2), and (iii) the usage of bridge deck surface as a proxy for bridge retrofit budget (Section 3.2.1).

\subsubsection{Network modifications}

A detailed examination of the IMN and the CRN of the previous study, SPR2480 , indicate that some modifications are necessary to both networks to ensure that they 
can be compared in a consistent manner. We discuss these modifications hereafter and finalize the networks used for the analysis in this study.

The CRN does not include two road segments of SR-37, which exist in the IMN. These are: (i) the road segment of SR-37 from Bedford south to Paoli, and (ii) the road segment of SR-37 from SR-64 south to I-64 (Figure 3.1). These two segments are now added to the CRN.

The northern border of the original IMN, which is south of I-70, is substantially more south than the northern border of the original CRN, which is US-40. The implication is that many population centers which had been considered in SPR-2480 as part of the CRN (including the major population centers of Terra Haute, Brazil, and Greencastle) cannot be considered in the IMN in terms of population coverage or in terms of routing connectivity. This is now modified by adding to the IMN: (i) the road segment of I-70 from Illinois border to Cloverdale and (ii) the road segment of US-231 from Spencer to Greencastle. The modifications are indicated in Figure 3.2.

As the IMN is a sub-network of CRN, it does not have some of the links present in the CRN. This requires the population to be redistributed to only these links present in the IMN so as to cover the entire population using just the IMN. These population centers are now reassigned to their closest road links in the IMN. This implementation detail also makes population coverage easier to achieve in the IMN.

The aforementioned network modifications define the IMN and the CRN for this study, as shown in Figure 3.3. The parameters of the resulting transportation networks are 
indicated in Appendices A, B and C. The parameters of the population centers are indicated in Appendices D and E.

\subsubsection{Objective function weights}

The IMN considers two different objectives: travel time and coverage, under a limited budget constraint. These objectives do not necessarily move in the same direction. That is one may improve while the other deteriorates for a given solution in terms of bridge retrofit. Hence, trade-offs exist between these two objectives. From a practical standpoint this aspect is addressed by assigning different weights to these two objectives to indicate different levels of importance for each of them. This implies that the decision maker can select the level of importance given to each objective. Based on this perspective, the following pairs of weights ( $u_{1}$ for travel time, $u_{2}$ for coverage) were considered: (0.999,0.001), (0.995,0.005), (0.990,0.010), (0.9825,0.0175), (0.975,0.025), $(0.9500,0.0500)$ and $(0.900,0.100)$. The numerical value of the weights indicate the relative importance given to travel time and population coverage.

\subsubsection{Bridge deck surface as a proxy for bridge seismic retrofit budget}

The budget for bridge earthquake retrofitting is measured in terms of millions of square feet of bridge deck surface. The bridge deck surface is used as a proxy for the actual retrofitting costs which are not available. The problem is solved for budgets ranging from 1.67 million square feet of bridge deck (which is the least retrofitting investment for establishing connectivity among all major population centers) to 3.33 
million square feet (beyond which the marginal benefit of the investment is minimal) in increments of 0.33 million square feet of bridge deck surface.

\subsection{Computational results and analysis}

The numerical results for both the IMN and the CRN are illustrated in Figure 3.4 and provided in Appendix F. The following observations compare the performance of these two networks.

The CRN performs better in terms of travel time (lower travel times) for greater weights on the travel time criterion. This is due to the increased spatial solution space of the CRN (more links to select from, more available paths). The straightforward practical implication is that the CRN is better for first responder operations, when minimization of the response time is the sole objective. It is also noted here that for the low traffic volume of response operations, the IMN which, consists of multi-lane (greater deck) bridges, is less efficient to retrofit. The reverse is true when the high traffic volumes associated with the IMN are factored in. That is, the decision to retrofit almost all links of the IMN (as illustrated in Figures 3.6 to 3.11) is implied when the high daily volumes of traffic on the IMN links are accounted too. While this study (and SPR-2480) addresses only the earthquake response planning objectives, in reality, the day-to-day traffic volumes and their implied link capacities should be a bigger factor in identifying the critical links to retrofit.

The CRN provides greater flexibility to the decision maker as it has a lot more links from which to choose the critical link. Thereby, it has a greater total travel time range, from 1320 to 1780 minutes, while the IMN ranges from 1580 to 1750 minutes. 
The CRN has population coverage values ranging from 407,000 to 457,000 when the IMN ranges from 432,000 to 452,000.

The budget percentage required for retrofitting links of the CRN that belong to the IMN is very high (Figure 3.5). This indicates once more the expensive nature of IMN infrastructure, which is reasonable when the daily traffic volumes on them are factored into the decision making process by the traffic agency.

\subsection{Discussion}

In this chapter, the IMN was identified and correlated to the CRN of seismicprone southwest Indiana. The computational results indicated that the CRN provides a more flexible performance space for the decision makers due to its spatial extent and achieves greater globally optimum values (minimum travel time of 1320 minutes , maximum population coverage of 457.000) (Figure 3.4). Furthermore, the IMN has a necessary and dominating seismic retrofitting cost, even if considered as part of the CRN (Figure 3.5).

Concluding, the CRN performs better for the low volume emergency response operations since it provides a wider range of routing options (more road links) at a lower cost because it can avoid the retrofitting of the costly multi-lane INDOT maintained infrastructure. On the other hand, it is the IMN's high capacity infrastructure which can resume the post-earthquake high-volume and day-to-day industrial, cargo, commercial and commuting traffic volumes at regional, state and federal level. 


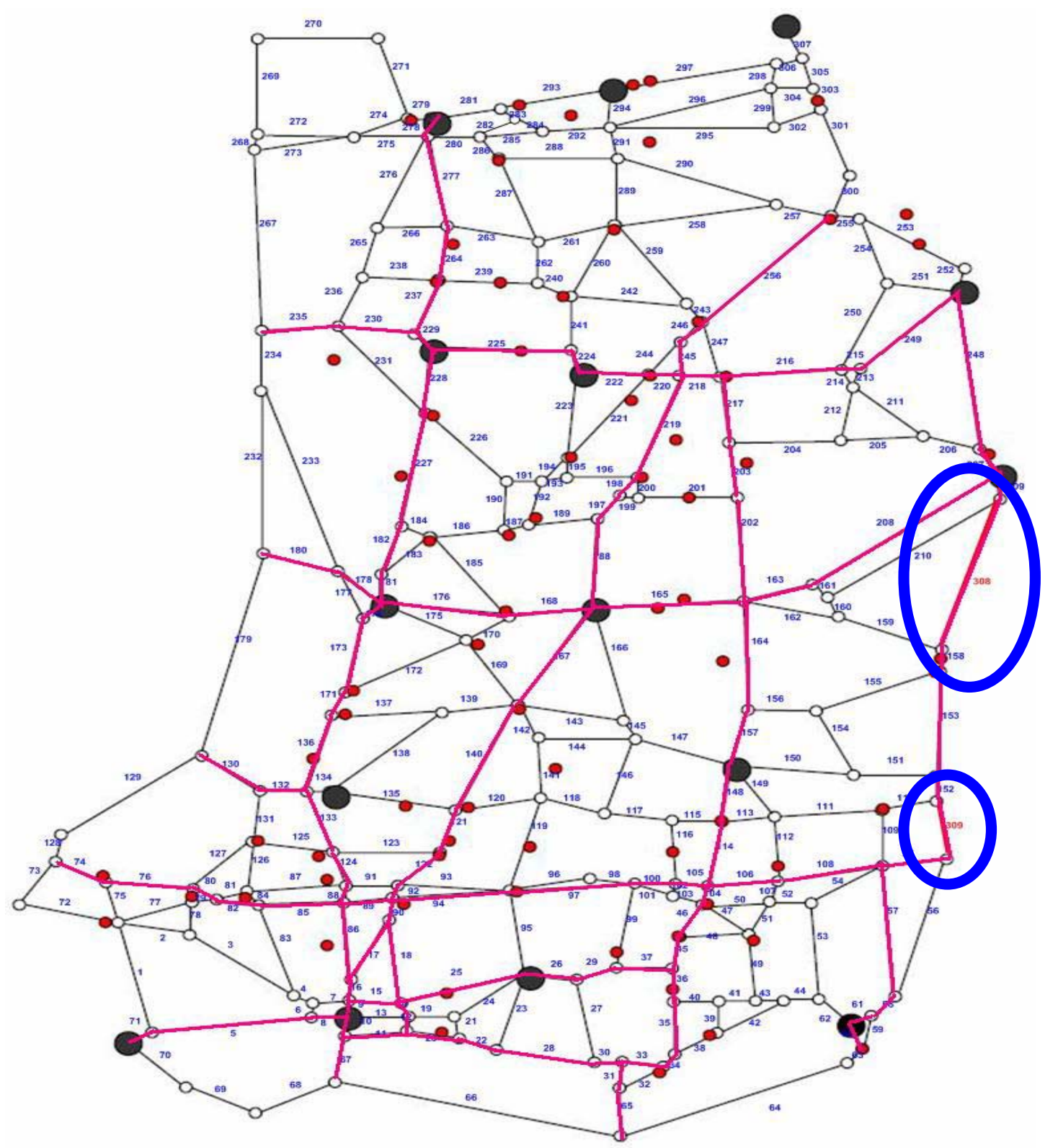

Figure 3.1. Two road segments of SR-37 existing in the IMN that are added to the CRN. 


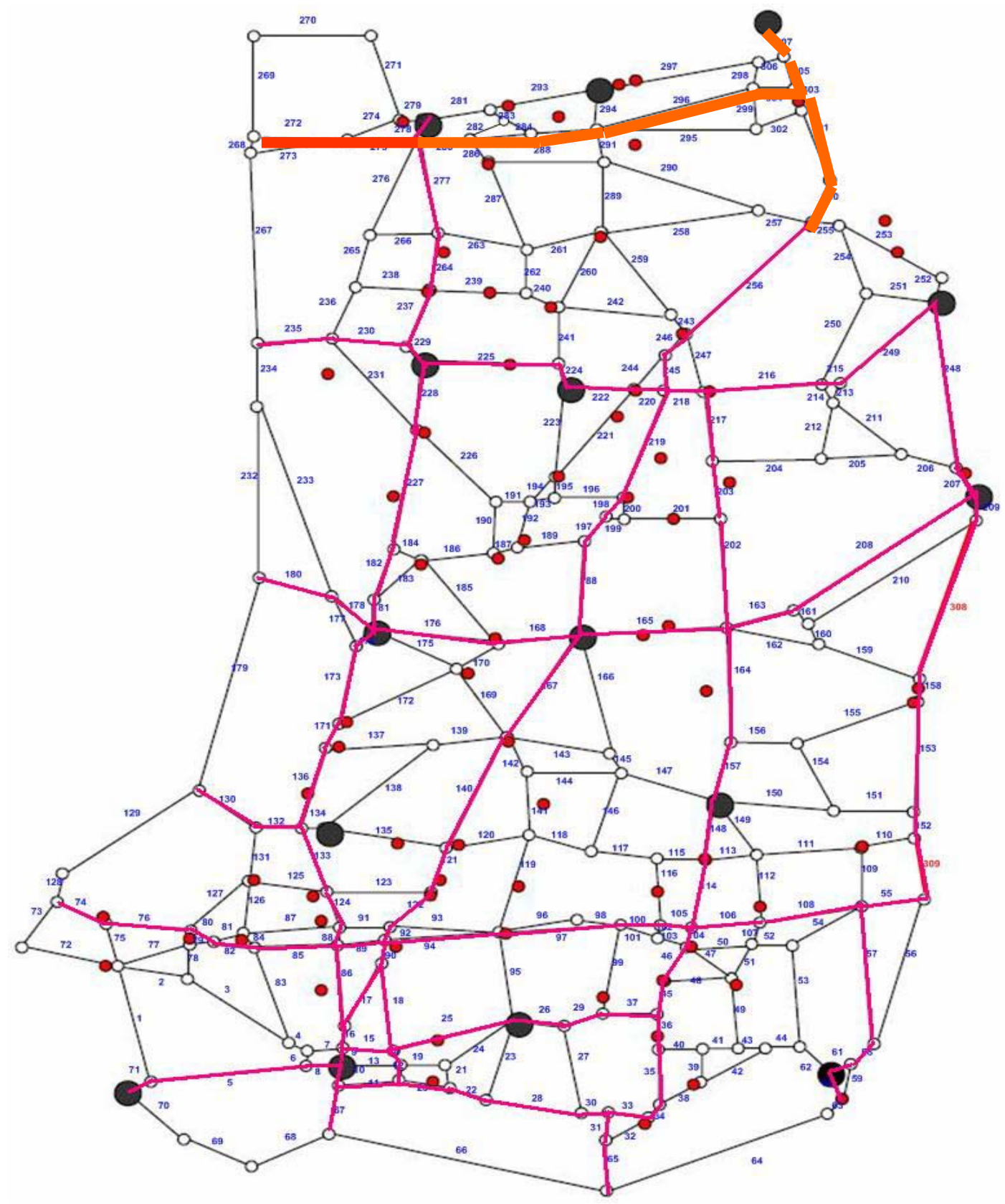

Figure 3.2. Modification of the northern border of the IMN (shown using the thick highlight). 


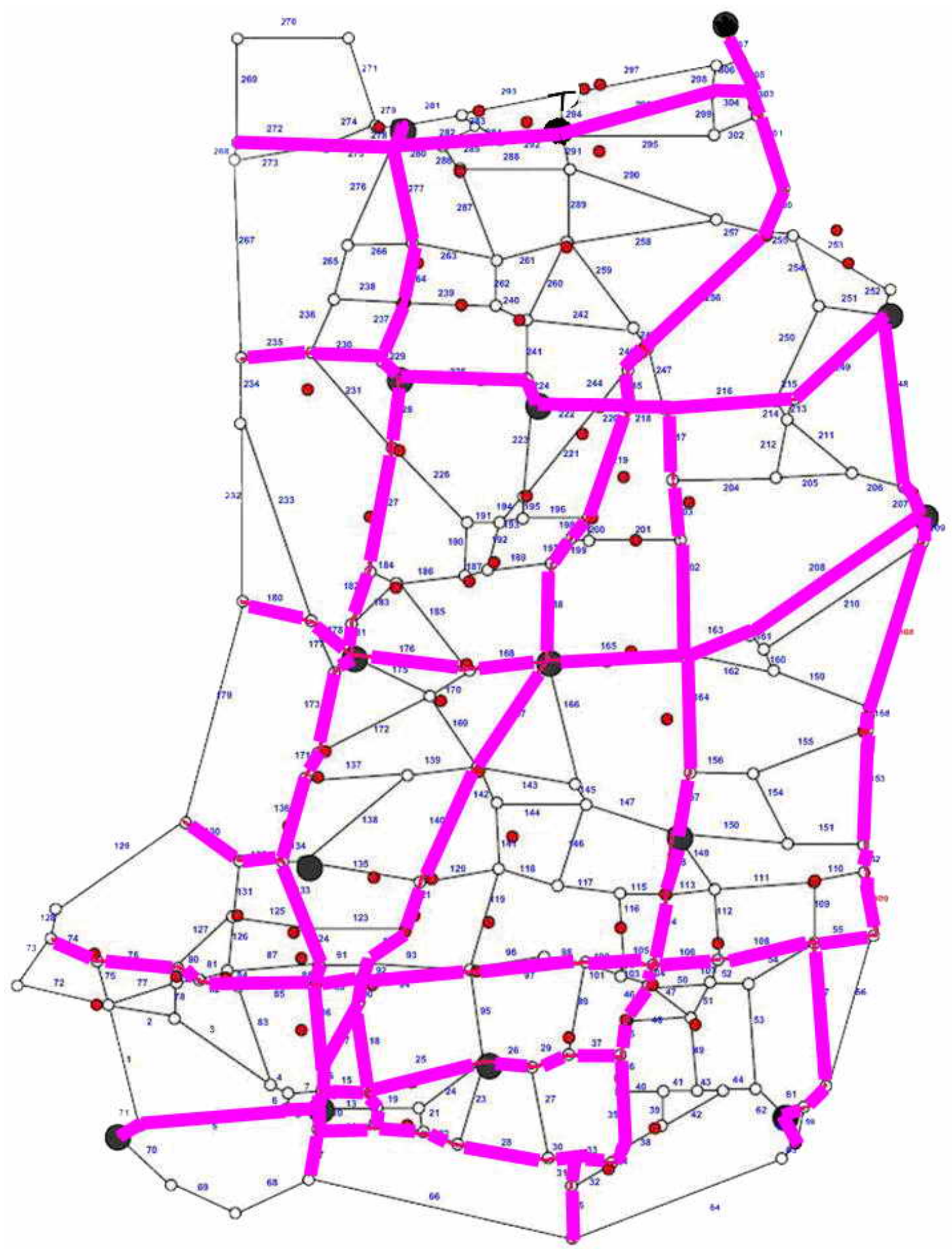

Figure 3.3. The CRN (all links) and the IMN (highlighted links). 


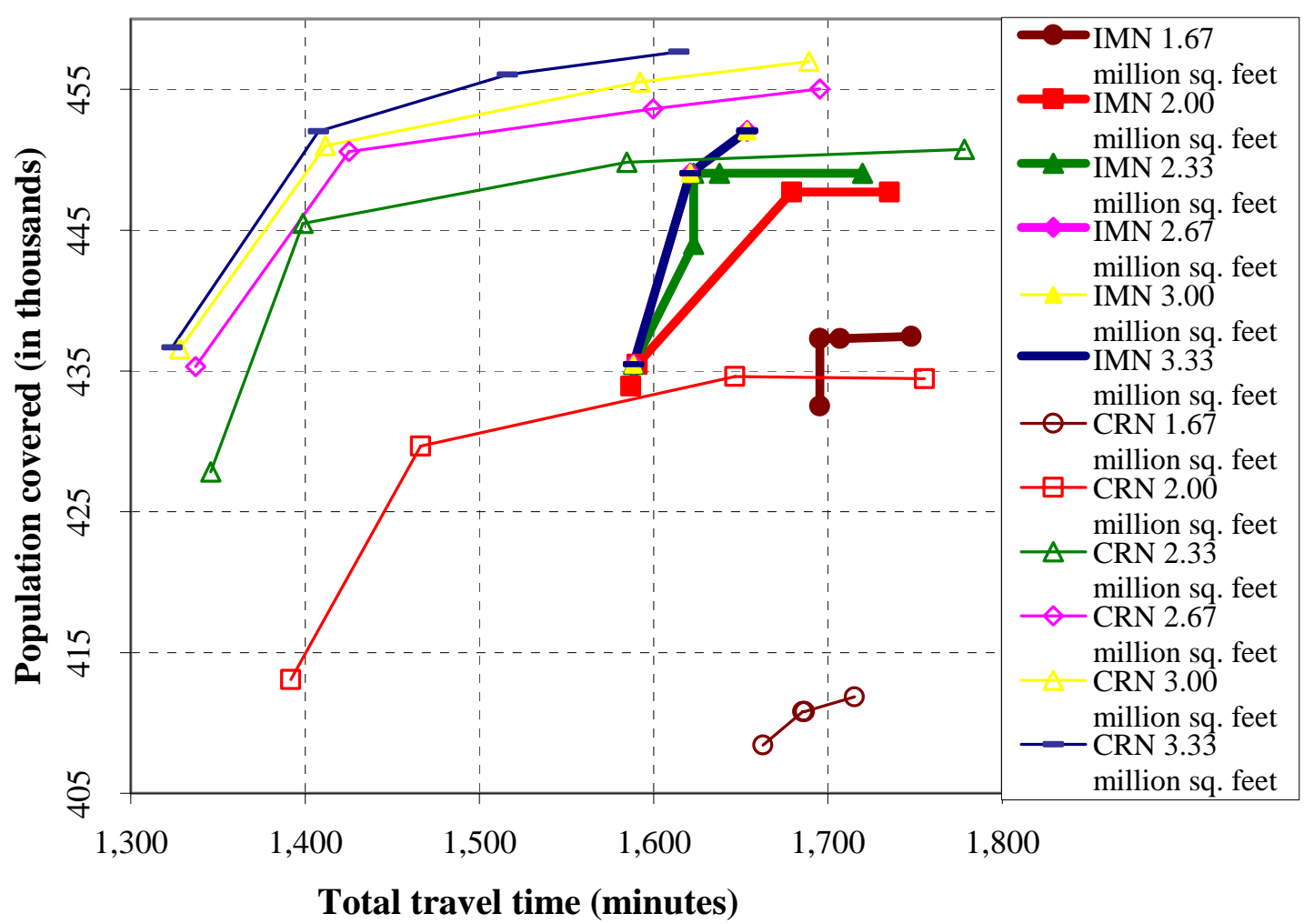

Figure 3.4. The set of non-inferior solutions for IMN and CRN. 


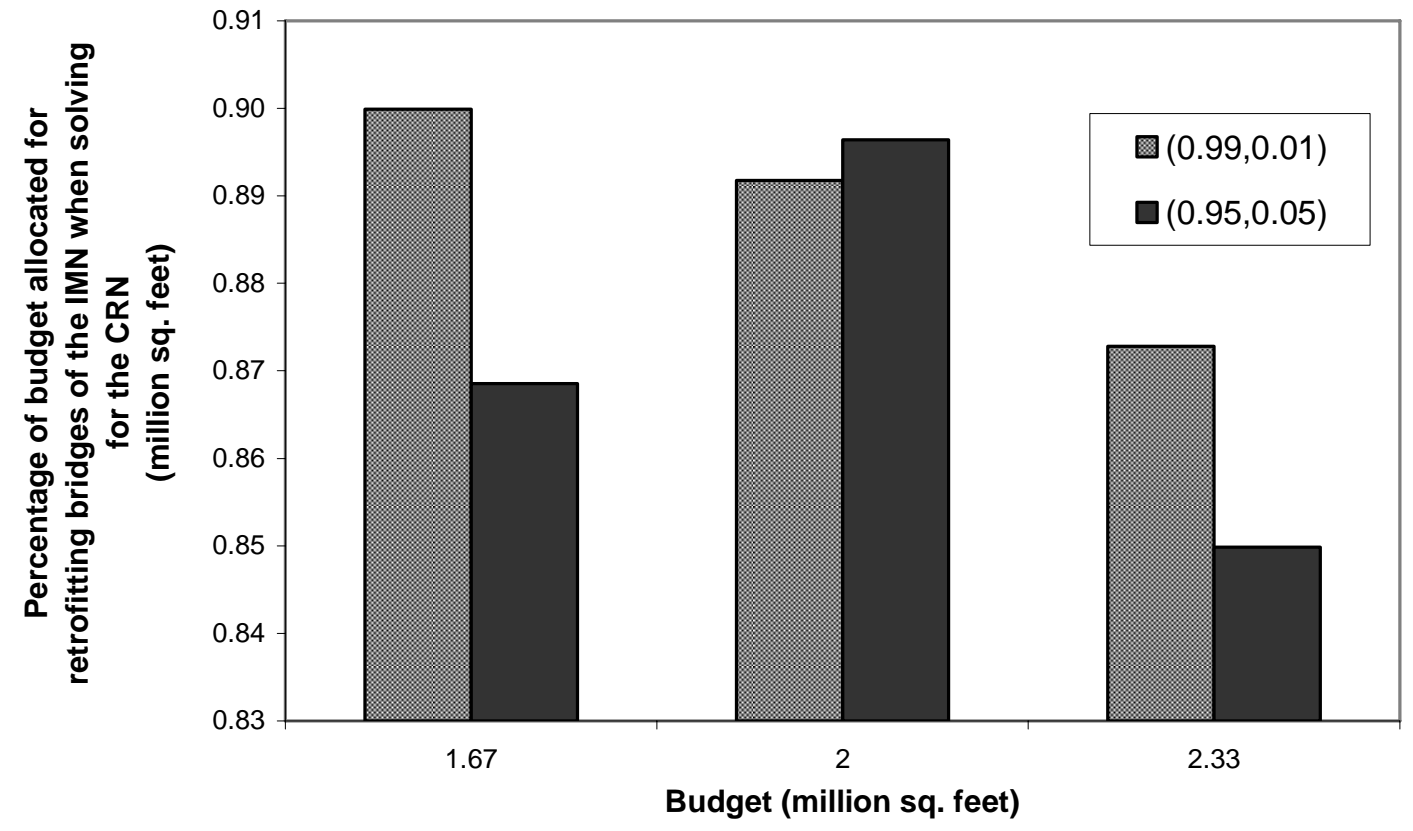

Figure 3.5. Percentage of the budget required for the CRN that belongs to the IMN. 


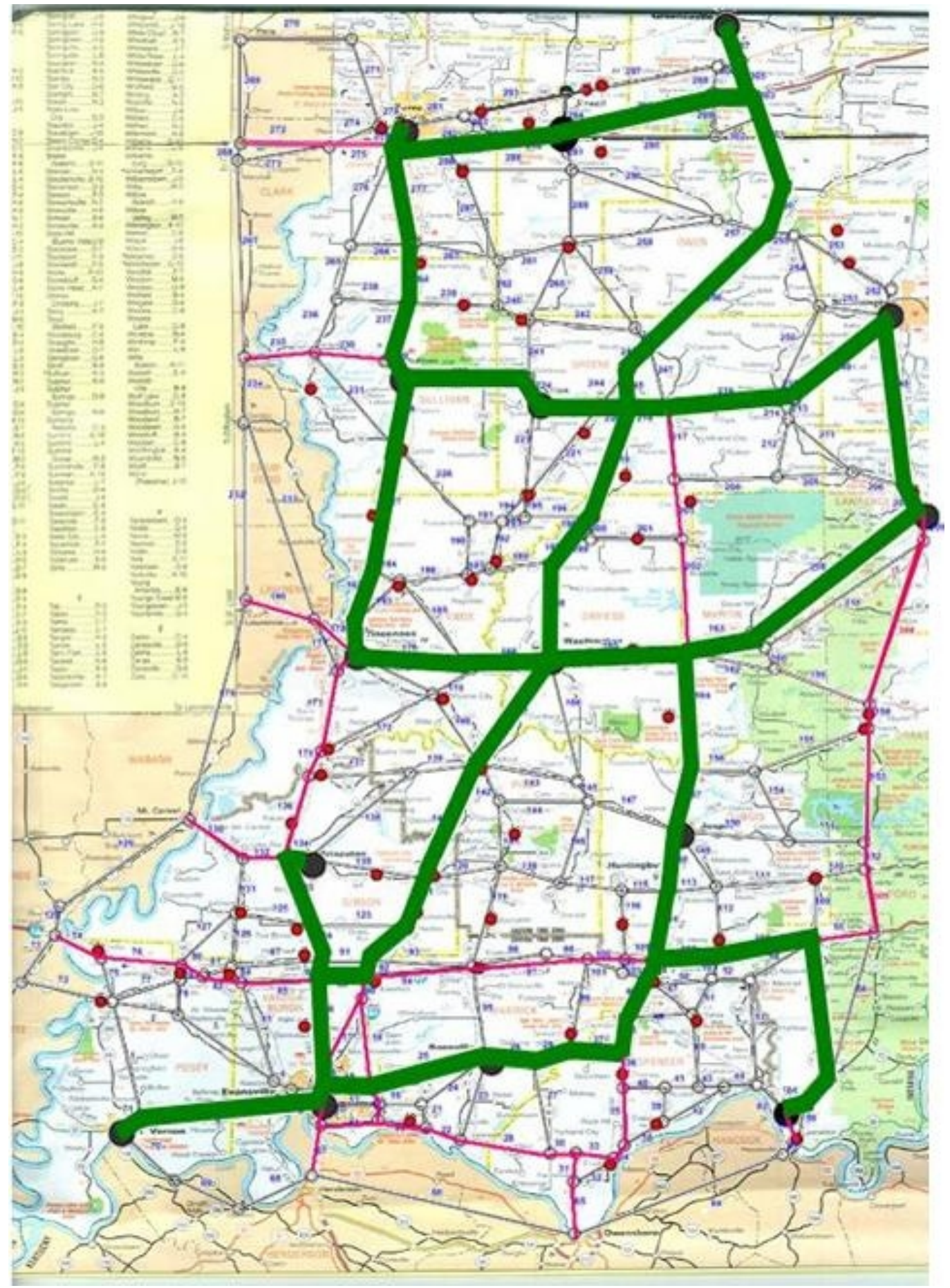

Figure 3.6. Critical routes for the weight pair $(0.999,0.001)$ and budget 1.67 million sq. feet in the IMN. 


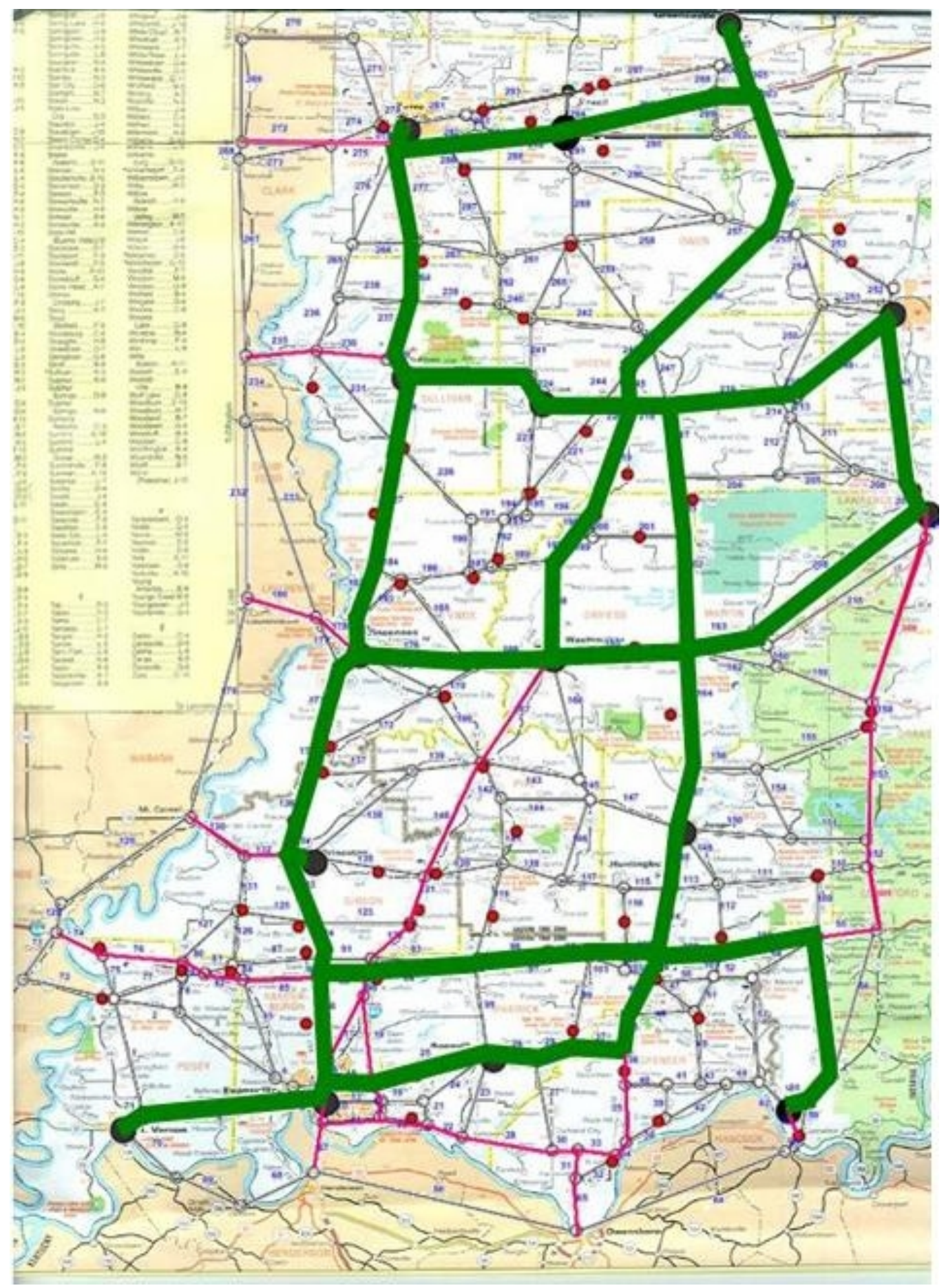

Figure 3.7. Critical routes for the weight pair $(0.990,0.010)$ and budget 2.00 million sq. feet in the IMN. 


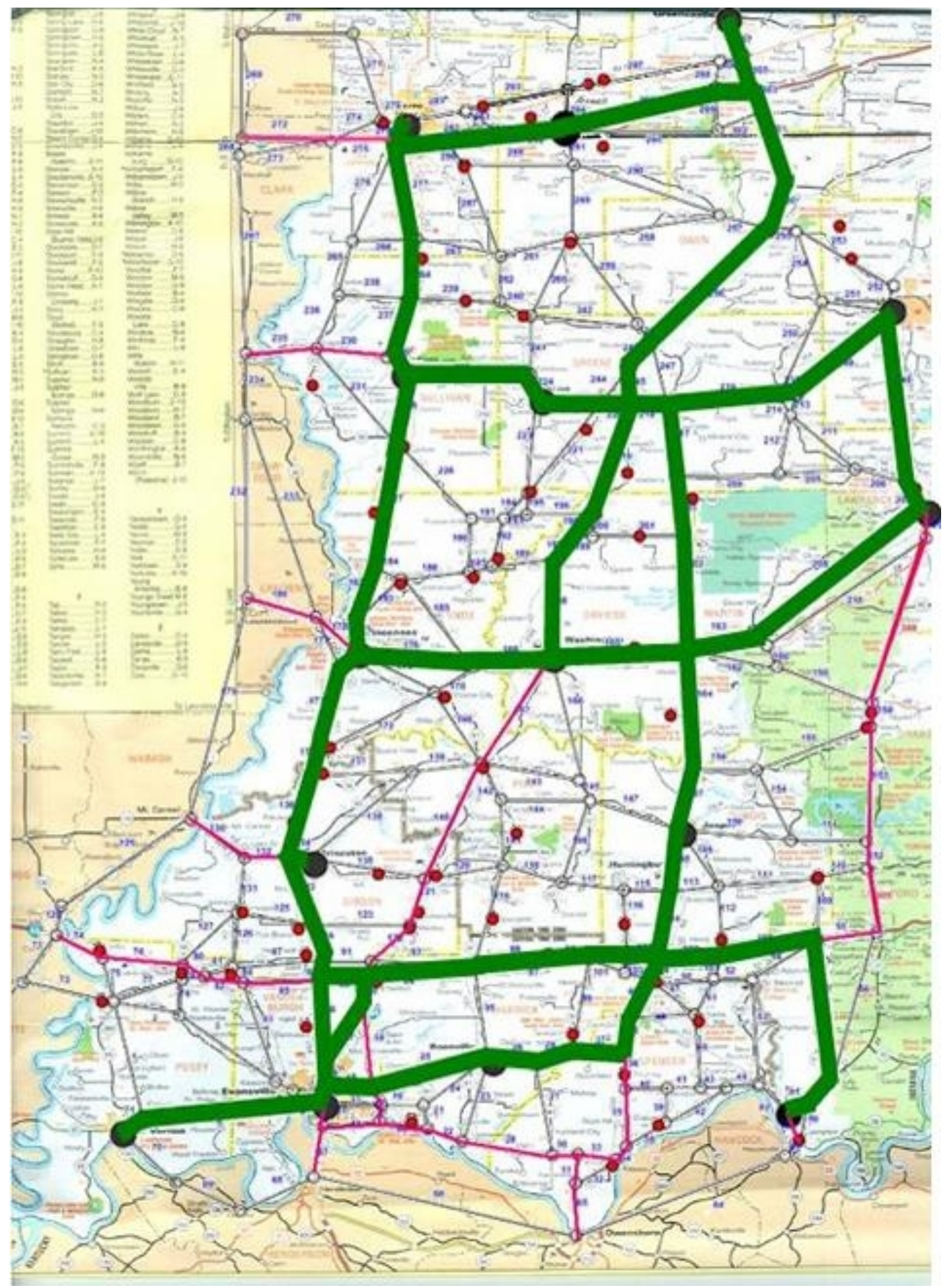

Figure 3.8. Critical routes for the weight pair $(0.999,0.001)$ and budget 2.00 million sq. feet in the IMN. 


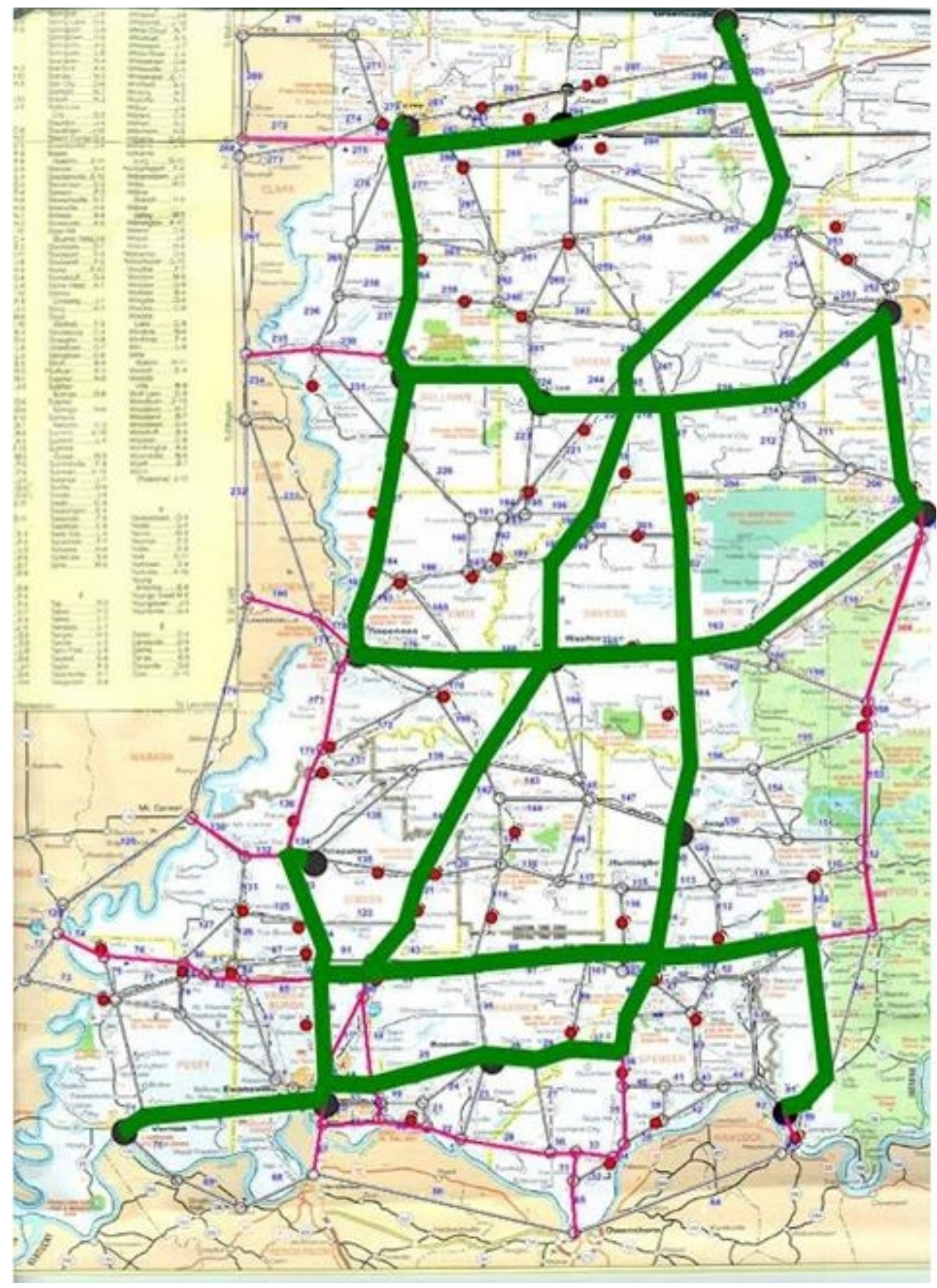

Figure 3.9. Critical routes for the weight pair $(0.990,0.010)$ and budget 2.33 million sq. feet in the IMN. 


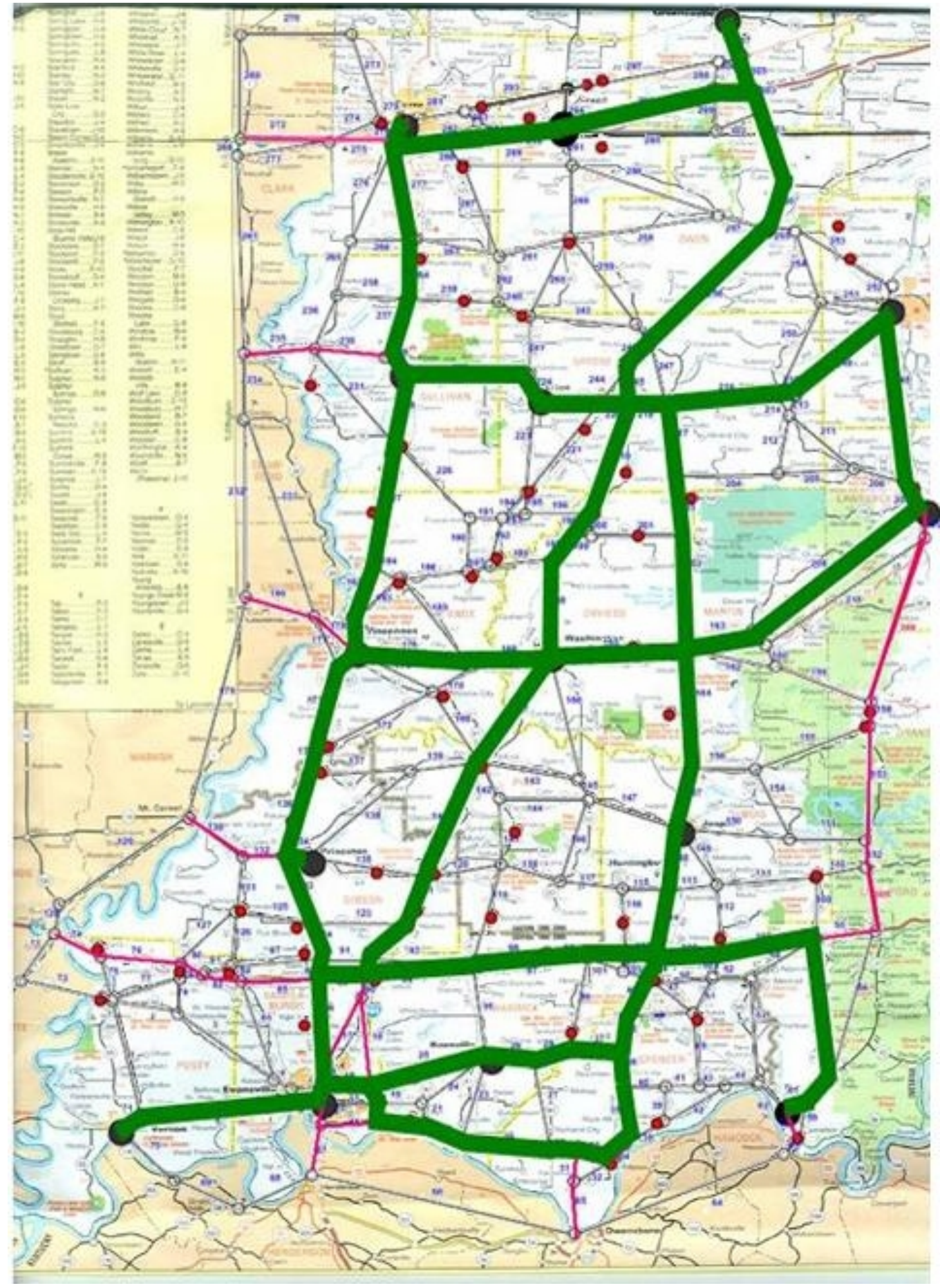

Figure 3.10. Critical routes for the weight pair $(0.983,0.017)$ and budget 2.63 million sq. feet in the IMN. 


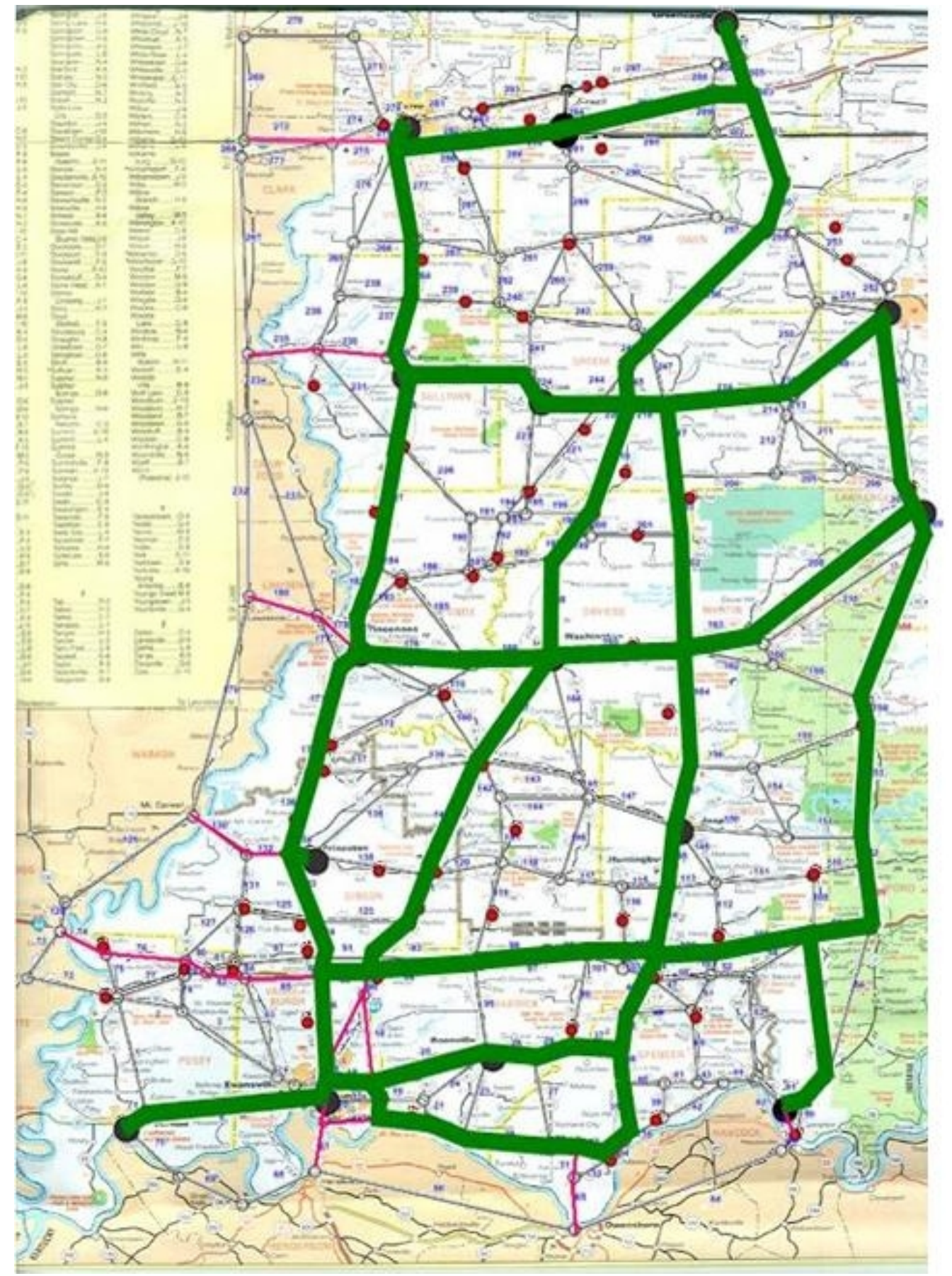

Figure 3.11. Critical routes for the weight pair $(0.995,0.005)$ and budget 3.33 million sq. feet in the IMN. 


\section{CHAPTER 4. DYNAMIC REROUTING}

Chapter 4 studies the problem of dynamically rerouting first responders or traffic for arbitrary scenarios or actual events, identified by INDOT, where part of a route is unavailable due to the specific earthquake characteristics. This objective provides backup operational response actions when specific road segments of the recommended primary route network fail.

In Section 4.1 the methodological framework is defined and the components of the methodological framework are described. In Section 4.2 the operational flow chart is summarized. In Section 4.3 the mathematical formulation of the corresponding optimization problem is modeled. In Section 4.4 the solution methodology is described. The chapter ends with a concluding discussion in Section 4.5. The GAMS/CPLEX optimization software is used to calculate the dynamic routes, for which internet resources, code and the user manual is provided in Appendices G, H and I.

\subsection{Methodological framework}

The problem of dynamically rerouting vehicles in a network with unknown link availability status can produce an arbitrarily large number of scenarios, each corresponding to the combination of different availability statuses among all links in the network. Since this number grows exponentially, the number of potential scenarios 
becomes prohibiting for operational applications. It is estimated that even if all scenarios have been pre-calculated and saved efficiently in an electronic format, the access time at the time needed will still be non-trivial. On the contrary, compared to the time accessing a large database, the computational time for the framework proposed is considered to be significantly lower, thus more efficient for real-time operations. It is noted that the key characteristic of the problem is that the final status of the links in the network is unknown until the actual earthquake event. Only after part of the network status has been verified, exact routing operations become available.

The methodological framework consists of 6 components: 1) a static database for storing the network topology, 2) a dynamic database for storing and updating the network status, 3) the optimization component responsible for calculating and proposing the dynamic routes, 4) the verification of the availability status of the proposed routes, 5) the updating of the dynamic network status database for the case that certain links in the proposed routes have not been verified, and 6) the final verified dynamic routes.

\subsubsection{Network topology static database}

In the network topology static database, the road network before the earthquake is stored. It contains the set of nodes defining the network and the set of links with their travel times. Those data are considered to be known before the event of an earthquake, therefore they do not need to be updated after the event of the earthquake. This database has to be updated only when new links are constructed or have been considered abandoned. 


\subsubsection{Dynamic network status database}

In the dynamic network status database, the status of the road network after the earthquake is stored. It contains 2 parameters for each link, one defining the link status and one defining whether the link has been verified. Initially, it is considered that all links are available and that their status has not been verified. This initialization is selected because the first proposed paths are simply the shortest paths of the initial pre-earthquake network. Then only the unverified links on the proposed routes will have to be verified. This process helps responders to focus strictly on verifying the availability of the links in the optimal routes only, rather than spending precious response time trying to verify the status of links that will not be included in the optimal routes. It is highlighted that the dynamic database has to be initialized before every mock or actual earthquake response operation as previously described. Finally, in the case that certain links are not available for response operations before the event of the earthquake (due to major maintenance works or other accidents and events), they can be defined in the dynamic network status database as non-available and verified.

\subsubsection{Optimization component}

The optimization component is responsible for calculating the optimal routes given the network status. The optimization component does not identify whether the proposed routes are including links whose status has not been verified. As will be described in later sections, the multi-commodity uncapacitated shortest path problem is solved, which is decomposed to multiple shortest paths. Very efficient algorithms exist 
for the shortest path problem which is solved multiple times in a short time duration. The CPLEX optimization software is used.

\subsubsection{Proposed route verification component}

The route verification component is responsible for verifying the status of the links in the proposed routes. If the status of a link(s) in the proposed route has not been verified, then an appropriate file output is generated that asks the controller to verify the availability status of the unverified link(s). If the status of all links in the proposed routes has been verified, then the optimal verified routes are released.

\subsubsection{Network status update}

This component corresponds to the set of actions necessary for identifying the status of unverified links and inserting this information in the dynamic network status database. There are two pieces of information that are updated: a) the link verification status, which changes from unverified to verified, and b) the link availability status which can either remain as is (available) or change to unavailable if the link is verified to be unavailable. When these pieces of information are updated, then the optimization component will be capable of calculating an updated optimal proposal.

\subsubsection{Verified optimal routes}

This component is the final output of the dynamic rerouting methodological framework. Only after all links in the updated optimal routes have been verified, will the process converge to the final output. The optimal routes are given in the form of an output file, where the route of each origin-destination pair is specified. 


\subsection{Operational flow chart}

The operational flow chart of the proposed framework is illustrated in Figure 4.1 and summarized here.

Before an earthquake, the network topology static database is maintained up to date, thus realistically representing the current network. The network status dynamic database is updated by specifying the current availability status of all links and setting all links to be in unverified status.

Following an earthquake, the optimization component calculates the optimal routes considering the pre-earthquake network status. Then the component responsible for verifying the availability status of the links used in the proposed routes will identify which links in the proposed routes have not been verified. In the case that unverified links do exist, these links are made known to the controller. The controller is responsible for verifying the actual availability status of these links and then update the network status dynamic database accordingly. After the dynamic database is updated, the new optimal routes are calculated. The links in the proposed routes whose availability status has not been verified will have to be verified again by the controller. This process iterates till the availability status of all links in the proposed routes have been verified, and the optimal verified routes are made available.

\subsection{Mathematical formulation}

In this section the mathematical formulation for the optimal dynamic routes is described. 


\subsubsection{Problem statement}

The problem of defining the optimal dynamic routes seeks the fastest routes from the location of first responders to the affected population centers given the availability of the used links.

\subsubsection{Parameters}

Let $G(N, E)$ denote an undirected network with node set $N$ and link set $E$. The indices $i$ and $j$ denote a node in the network, $i, j \in N$ and $E \subseteq N \times N$, where $[i, j]$ denotes an undirected link between nodes $i$ and $j$. Each O-D pair between the base of first responders and the affected population center in the network is represented as a unique commodity type. Let $k$ represent the commodity type index, $k \in K$, where $K$ denotes the set of all commodities. One unit of commodity flow $k$ must be transported over the network from its origin $O(k)$ to its destination $D(k)$. To differentiate the direction of flow of a commodity, we consider two directed links $(i, j)$ and $(j, i)$ corresponding to each original undirected link $[i, j]$. Let $A$ denote the set of the directed links. Each link $(i, j)$ has an associated nonnegative fixed travel time $t_{i j}^{k}$ which defers for each commodity due to the different operational speeds of different response vehicles. Moreover, all links are capacitated only by their availability status $s_{i j}$. If the link $(i, j)$ is available then $s_{i j}=1$, otherwise $s_{i j}=0$. Parameter $b_{i}^{k}$ denotes whether node $i$ is an origin (first responders' base), a destination (affected population center) or intermediate node for commodity $k$. If node $i$ is an origin for commodity $k$ then $b_{i}^{k}=-1$. If node $i$ is 
a destination for commodity $k$ then $b_{i}^{k}=1$. If node $i$ is an intermediate node for commodity $k$ then $b_{i}^{k}=0$.

\subsubsection{Decision variables}

The formulation contains a single set of variables, the arc flow variables denoted by the vector $x=\left\{x_{i j}^{k}\right\}$, which define the flow of different commodities in each of the selected links. If there is a unit flow of commodity $k$ on link $(i, j)$ then $x_{i j}^{k}=1$, otherwise $x_{i j}^{k}=0$.

\subsubsection{The dynamic rerouting formulation}

The dynamic rerouting formulation has a single objective, the minimization of the total travel time of all first responders' routes.

The integer programming formulation for the dynamic rerouting formulation is expressed as follows:

Minimize: $\quad \sum_{k \in K} \sum_{(i, j) \in E} t_{i j}^{k} \cdot x_{i j}^{k}$

Subject to:

$$
\begin{array}{lr}
\sum_{(i, j) \in A} x_{i j}^{k}-\sum_{(j, i) \in A} x_{j i}^{k}=b_{i}^{k} & \forall i \in N, \forall k \in K \\
x_{j i}^{k} \leq s_{i j} & \forall k \in K, \forall(i, j) \in A \\
x_{j i}^{k} \in\{0,1\} & \forall k \in K, \forall(i, j) \in A
\end{array}
$$


Constraint (4.2) is the conservation of flow for all commodities and nodes. Constraint (4.3) is the capacity constraint for the case that a link is not available (has failed due to the seismic activity). Finally, constraint (4.4) is the integrality constraint of the routing variables.

This formulation is classified as a multi-commodity uncapacitated shortest path problem. It is uncapacitated because the capacity constraint (4.3) does not refer to the summation of all commodity flow variables for a given link.

\subsection{Solution methodology}

The formulation of Section 4.3 has been classified as a multi-commodity uncapacitated shortest path problem. This formulation does not contain a bounding constraint among the flow variables of the different commodities. Therefore, it can be decomposed to multiple independent instances of the shortest path problem, one instance for each commodity flow. Furthermore, since the shortest path formulation has a totally unimodular constraint matrix, the integrality constraint (4.4) can be linearly relaxed.

The formulation for each commodity $k$ (response route) is:

Minimize: $\quad \sum_{(i, j) \in E} t_{i j}^{k} \cdot x_{i j}^{k}$

Subject to:

$$
\begin{array}{lr}
\sum_{(i, j) \in A} x_{i j}^{k}-\sum_{(j, i) \in A} x_{j i}^{k}=b_{i}^{k} & \forall i \in N \\
x_{j i}^{k} \leq s_{i j} & \forall(i, j) \in A
\end{array}
$$


$x_{j i}^{k} \geq 0$

$\forall(i, j) \in A$

The objective is the minimization of the total time for each individual route. Constraint (4.5) is the conservation of flow for nodes. Constraint (4.3) is the capacity constraint for the case that a link is not available (has failed due to the seismic activity). Finally, constraint (4.4) is the non-negativity constraint of the linear routing variables.

This formulation is solved separately for each commodity $k$ by applying a shortest path algorithm (Ahuja et al, 1993).

\subsection{Discussion}

This chapter describes the methodological framework for defining the optimal dynamic routes after an earthquake. It consists of 6 methodological components: 1) the static database for storing the network topology, 2) the dynamic database for storing and updating the network status, 3) the optimization component responsible for calculating and proposing the dynamic routes, 4) the verification of the availability status of the proposed routes, 5) the updating of the dynamic network status database in case that certain links in the proposed routes have not been verified, and 6) the final verified dynamic routes. In brief, given the network status, the process iterates until the availability status of all links in the proposed routes have been verified. The corresponding formulation is reduced to multiple shortest paths; one shortest path computation for each first responder's route. The GAMS/CPLEX optimization software 
is used to calculate the dynamic routes, for which internet resources, code and the user manual is provided in Appendices G, H and I. 


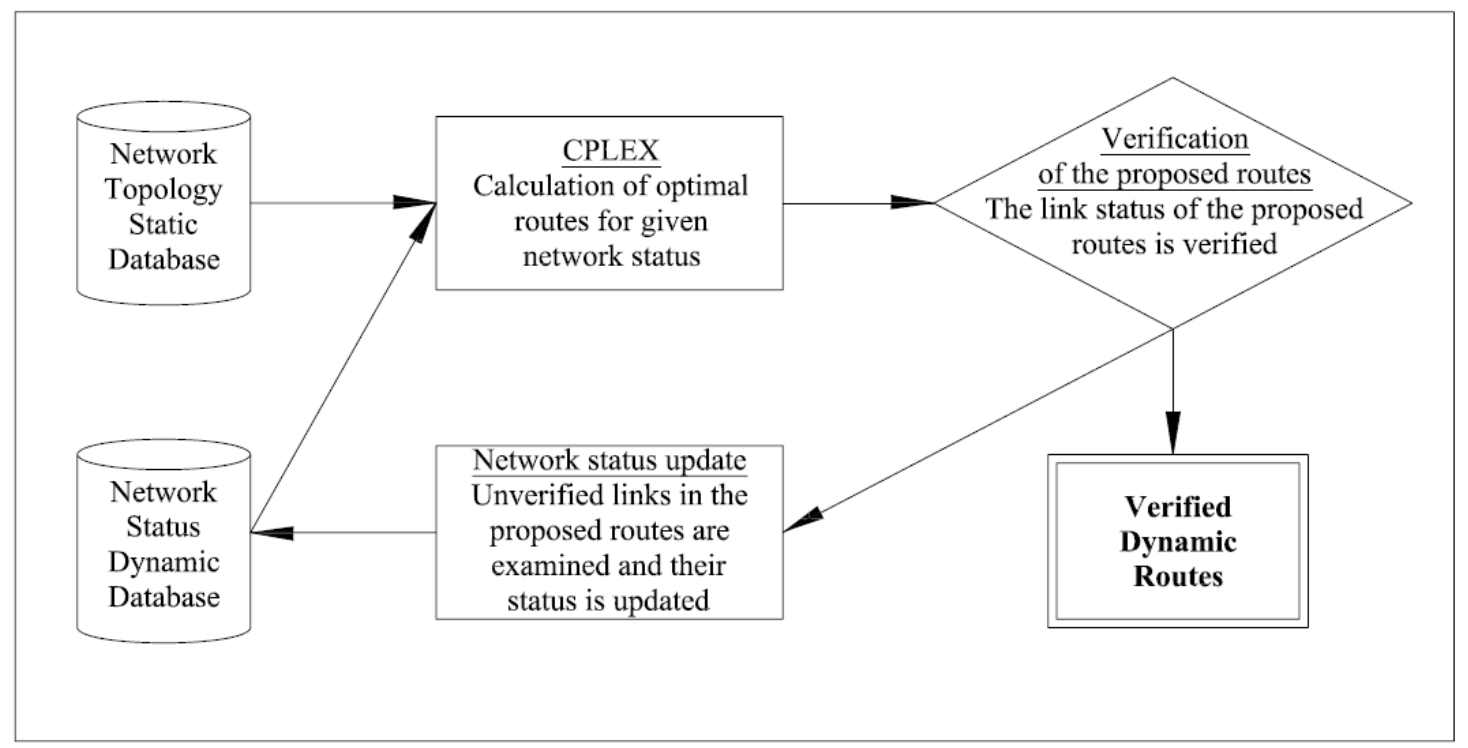

Figure 4.1. Operational flow chart for the calculation of the optimal dynamic routes. 


\section{CHAPTER 5. CONCLUSIONS}

This chapter summarizes the research, highlights its contributions, and proposes directions for future research.

\subsection{Summary}

This study addressed two objectives. The first objective had a planning perspective while the second objective had an operational perspective.

The first objective was to compare the performance of the IMN with the performance of the CRN of the seismic prone Vincennes district in southwest region of Indiana. This objectives identifies which bridges should be retrofitted before an earthquake, given a limited budget, so that connectivity and population coverage is ensured in the surviving road network after the earthquake.

The following conclusions are summarized from the comparison of the IMN and the CRN (Section 3.3) : (i) the CRN performs better for emergency response operations, where response time is the critical objective, (ii) the CRN provides a wider range of first responders routing and population coverage options, (iii) the cost of retrofitting links belonging to the IMN is a significant percentage of the total budget allocated for the CRN (Figure 3.5), and (iv) the IMN has the high capacity infrastructure that have high daily 
volumes; so this infrastructure is important for resuming normal traffic operations after an earthquake.

The second objective was to determine a methodological framework to dynamically reroute first responders when part of a route is unavailable after the earthquake. This objective provides back-up operational response actions when specific road segments of the recommended primary route network fail during an actual earthquake.

The methodological framework is illustrated in the flow chart of Figure 4.1, and summarized hereafter. Before an earthquake, the network topology static database is maintained up to date, thus realistically representing the current network. The network status dynamic database is updated by specifying the current availability status of all links and setting all links to be in unverified status.

Following an earthquake, the optimization component calculates the optimal routes considering the pre-earthquake network status. Then the component responsible for verifying the availability status of the links used in the proposed routes will identify which links in the proposed routes have not been verified. In the case that unverified links do exist, these links are made known to the controller. The controller is responsible for verifying the actual availability status of these links and then update the network status dynamic database accordingly. After the dynamic database is updated, the new optimal routes are calculated. The links in the proposed routes whose availability status has not been verified will have to be verified again by the controller. This process iterates till the 
availability status of all links in the proposed routes have been verified, and the optimal verified routes are made available.

\subsection{Contributions of the research}

In this study an improved formulation for the MCMCNDP was built and a methodological framework and software was developed for the dynamic rerouting of first responders.

The contributions of the research are: (i) the formulation of a mathematical program capable of eliminating all sub-tours in a single computational step (Section 2.4), (ii) the linear relaxation of the binary variables defining coverage and the decision of retrofitting a link (Section 2.4), reducing the computational complexity of the formulation (from integer to mixed integer), (iii) the development of a methodological framework and software for the dynamic rerouting of first responders (Section 4.1), and (iv) the classification of the dynamic rerouting problem as a multi commodity uncapacitated shortest path problem (Section 4.4) which decomposes to multiple independent shortest path problems.

\subsection{Future research directions}

The research addressed the problem of pre-event planning and post-event operations for the event of an earthquake. It is proposed that the research is integrated into a single decision support system (DSS) which is user-friendly for both planning and operational response. This will aid the actual training of the emergency response agencies. Training is an essential component of emergency response operations. A 
complete DSS will familiarize the emergency response agencies with the operations following an earthquake and minimize the response times.

Finally, from a holistic perspective, the long-term survival of the local economy after an earthquake does not depend merely on the effectiveness of the initial emergency response operations. More importantly, the daily traffic volumes on the links should be factored when making retrofit decisions. This is because while earthquakes are rare, the day-to-day usage of a link is of greater importance to the transportation agency. Hence, while earthquake response planning has a limited set of objectives, the transportation agency should take a holistic perspective to identify the critical links for seismic retrofit. This highlights the importance of the links of the IMN. 


\section{REFERENCES}

R. K. Ahuja, T. L. Magnanti, J. B. Orlin, (1993). Network Flows: Theory Algorithms and Applications, Prentice Hall.

Garcia, L.A., Sozen, M.A. and Ramirez, J.A. (2004). Emergency Earthquake Routes for the State of Indiana; Part II: Route Seismic Vulnerability Aspects, JTRP Draft Final.

Report FHWA/INDOT-2003/22.

Peeta, S. and Viswanath, K. (2004). Emergency Earthquake Routes for the State of Indiana; Part I: Criteria for Selection of Primary Routes: Transportation Aspects, JTRP

Draft Final Report FHWA/INDOT-2003/22.

Viswanath K. and Peeta S., 2003. The multicommodity maximal covering network design problem for planning critical routes for earthquake response. Transportation Research Record, 1857, p. 1-10.

Wong, R.T., (1980). Integer programming formulations of the travelling salesman problem, Proc. IEEE Conf. on Circuits and Computers, p. 149-152. 
APPENDIX 
APPENDIX A: NETWORK DATA

\begin{tabular}{|c|c|c|c|c|c|c|c|}
\hline Arc ID & \begin{tabular}{|c|} 
Origin \\
node \\
ID
\end{tabular} & $\begin{array}{c}\text { Destination } \\
\text { node ID }\end{array}$ & $\begin{array}{c}\text { Link } \\
\text { length } \\
\text { (miles) }\end{array}$ & $\begin{array}{c}\text { Speed } \\
(\text { miles/hr) }\end{array}$ & $\begin{array}{c}\text { Travel } \\
\text { time } \\
\text { (min) }\end{array}$ & $\begin{array}{l}\text { Bridge area } \\
\text { (sq. feet) }\end{array}$ & $\begin{array}{c}\text { INDOT- } \\
\text { Maintained }\end{array}$ \\
\hline 1 & 1 & 2 & 14.20 & 55 & 15.49 & 12555 & No \\
\hline 2 & 2 & 3 & 8.50 & 50 & 10.20 & 4299 & No \\
\hline 3 & 3 & 4 & 11.50 & 50 & 13.80 & 19422 & No \\
\hline 4 & 5 & 4 & 2.10 & 45 & 2.80 & 29279 & $\mathrm{No}$ \\
\hline 5 & 6 & 1 & 17.00 & 55 & 18.55 & 179029 & Yes \\
\hline 6 & 6 & 5 & 1.75 & 45 & 2.33 & 0 & No \\
\hline 7 & 7 & 5 & 4.00 & 45 & 5.33 & 61507 & $\mathrm{No}$ \\
\hline 8 & 8 & 6 & 3.10 & 45 & 4.13 & 139483 & Yes \\
\hline 9 & 8 & 7 & 1.50 & 45 & 2.00 & 7535 & Yes \\
\hline 10 & 8 & 9 & 2.40 & 45 & 3.20 & 15554 & Yes \\
\hline 11 & 9 & 10 & 5.70 & 65 & 5.26 & 104892 & Yes \\
\hline 12 & 11 & 10 & 1.54 & 65 & 1.42 & 26414 & Yes \\
\hline 13 & 8 & 11 & 5.00 & 45 & 6.67 & 55407 & No \\
\hline 14 & 11 & 12 & 1.72 & 65 & 1.59 & 43672 & Yes \\
\hline 15 & 12 & 7 & 4.00 & 45 & 5.33 & 0 & Yes \\
\hline 16 & 7 & 13 & 3.60 & 45 & 4.80 & 33124 & Yes \\
\hline 17 & 13 & 14 & 8.20 & 55 & 8.95 & 8059 & Yes \\
\hline 18 & 12 & 14 & 9.90 & 65 & 9.14 & 190749 & Yes \\
\hline 19 & 11 & 15 & 3.40 & 55 & 3.71 & 0 & No \\
\hline 20 & 10 & 16 & 4.30 & 45 & 5.73 & 0 & Yes \\
\hline 21 & 15 & 16 & 3.20 & 45 & 4.27 & 0 & No \\
\hline 22 & 16 & 17 & 2.90 & 55 & 3.16 & 11315 & Yes \\
\hline 23 & 17 & 18 & 9.60 & 55 & 10.47 & 21530 & No \\
\hline 24 & 15 & 18 & 8.90 & 50 & 10.68 & 1087 & No \\
\hline 25 & 12 & 18 & 11.40 & 55 & 12.44 & 10223 & Yes \\
\hline 26 & 18 & 19 & 5.20 & 50 & 6.24 & 5673 & Yes \\
\hline 27 & 19 & 20 & 10.50 & 50 & 12.60 & 27842 & No \\
\hline 28 & 17 & 20 & 8.90 & 55 & 9.71 & 66339 & Yes \\
\hline 29 & 19 & 21 & 5.20 & 50 & 6.24 & 9998 & Yes \\
\hline 30 & 20 & 22 & 3.30 & 55 & 3.60 & 0 & Yes \\
\hline
\end{tabular}




\begin{tabular}{|c|c|c|c|c|c|c|c|}
\hline 31 & 22 & 23 & 3.00 & 55 & 3.27 & 0 & Yes \\
\hline 32 & 23 & 24 & 5.10 & 50 & 6.12 & 1134 & No \\
\hline 33 & 22 & 24 & 3.40 & 55 & 3.71 & 3512 & Yes \\
\hline 34 & 24 & 25 & 1.20 & 55 & 1.31 & 2288 & Yes \\
\hline 35 & 25 & 26 & 6.80 & 55 & 7.42 & 0 & Yes \\
\hline 36 & 26 & 27 & 4.70 & 55 & 5.13 & 14055 & Yes \\
\hline 37 & 21 & 27 & 3.80 & 50 & 4.56 & 11421 & Yes \\
\hline 38 & 25 & 28 & 4.90 & 45 & 6.53 & 9254 & No \\
\hline 39 & 29 & 28 & 3.90 & 50 & 4.68 & 4141 & No \\
\hline 40 & 26 & 29 & 3.80 & 50 & 4.56 & 5474 & No \\
\hline 41 & 29 & 30 & 3.30 & 50 & 3.96 & 3840 & No \\
\hline 42 & 28 & 31 & 7.70 & 55 & 8.40 & 10520 & No \\
\hline 43 & 30 & 31 & 2.60 & 50 & 3.12 & 0 & No \\
\hline 44 & 31 & 32 & 3.30 & 55 & 3.60 & 21273 & No \\
\hline 45 & 27 & 33 & 3.80 & 55 & 4.15 & 5048 & Yes \\
\hline 46 & 33 & 34 & 4.60 & 55 & 5.02 & 9820 & Yes \\
\hline 47 & 35 & 34 & 5.60 & 50 & 6.72 & 1445 & No \\
\hline 48 & 33 & 35 & 6.20 & 50 & 7.44 & 8182 & No \\
\hline 49 & 35 & 30 & 8.90 & 50 & 10.68 & 14859 & No \\
\hline 50 & 36 & 34 & 6.20 & 50 & 7.44 & 4136 & No \\
\hline 51 & 35 & 36 & 5.40 & 50 & 6.48 & 2852 & No \\
\hline 52 & 37 & 36 & 4.10 & 50 & 4.92 & 0 & No \\
\hline 53 & 32 & 37 & 13.80 & 50 & 16.56 & 18809 & No \\
\hline 54 & 38 & 37 & 8.70 & 50 & 10.44 & 22758 & No \\
\hline 55 & 39 & 38 & 6.00 & 50 & 7.20 & 36508 & Yes \\
\hline 56 & 40 & 39 & 19.10 & 55 & 20.84 & 0 & No \\
\hline 57 & 40 & 38 & 17.00 & 50 & 20.40 & 30678 & Yes \\
\hline 58 & 41 & 40 & 3.40 & 55 & 3.71 & 0 & Yes \\
\hline 59 & 42 & 41 & 4.20 & 50 & 5.04 & 0 & No \\
\hline 60 & 42 & 43 & 3.40 & 45 & 4.53 & 1968 & Yes \\
\hline 61 & 43 & 41 & 2.10 & 45 & 2.80 & 0 & Yes \\
\hline 62 & 32 & 43 & 3.40 & 55 & 3.71 & 1440 & No \\
\hline 63 & 44 & 42 & 2.30 & 55 & 2.51 & 0 & No \\
\hline 64 & 45 & 44 & 29.00 & 55 & 31.64 & 0 & No \\
\hline 65 & 23 & 45 & 5.30 & 55 & 5.78 & 50352 & Yes \\
\hline 66 & 46 & 45 & 28.00 & 55 & 30.55 & 0 & No \\
\hline 67 & 9 & 46 & 10.00 & 55 & 10.91 & 332268 & Yes \\
\hline 68 & 46 & 47 & 9.30 & 50 & 11.16 & 0 & No \\
\hline 69 & 47 & 48 & 7.90 & 50 & 9.48 & 0 & No \\
\hline 70 & 48 & 49 & 8.70 & 50 & 10.44 & 0 & No \\
\hline 71 & 49 & 1 & 1.50 & 45 & 2.00 & 35411 & Yes \\
\hline 72 & 2 & 50 & 7.00 & 50 & 8.40 & 0 & No \\
\hline
\end{tabular}




\begin{tabular}{|c|c|c|c|c|c|c|c|}
\hline 73 & 50 & 51 & 6.00 & 50 & 7.20 & 0 & No \\
\hline 74 & 52 & 51 & 4.00 & 65 & 3.69 & 65623 & Yes \\
\hline 75 & 2 & 52 & 5.20 & 50 & 6.24 & 0 & No \\
\hline 76 & 53 & 52 & 8.00 & 65 & 7.38 & 188478 & Yes \\
\hline 77 & 2 & 54 & 7.50 & 50 & 9.00 & 55997 & No \\
\hline 78 & 3 & 54 & 3.90 & 50 & 4.68 & 2230 & No \\
\hline 79 & 54 & 55 & 1.70 & 50 & 2.04 & 2200 & No \\
\hline 80 & 55 & 53 & 1.80 & 65 & 1.66 & 22618 & Yes \\
\hline 81 & 55 & 56 & 3.00 & 50 & 3.60 & 0 & No \\
\hline 82 & 55 & 57 & 4.00 & 65 & 3.69 & 32003 & Yes \\
\hline 83 & 4 & 57 & 11.70 & 50 & 14.04 & 960 & No \\
\hline 84 & 57 & 56 & 2.50 & 50 & 3.00 & 15712 & No \\
\hline 85 & 57 & 58 & 7.30 & 65 & 6.74 & 29832 & Yes \\
\hline 86 & 13 & 58 & 8.40 & 55 & 9.16 & 21264 & Yes \\
\hline 87 & 56 & 59 & 9.40 & 50 & 11.28 & 2227 & No \\
\hline 88 & 58 & 59 & 2.00 & 55 & 2.18 & 1600 & Yes \\
\hline 89 & 58 & 60 & 4.50 & 65 & 4.15 & 37137 & Yes \\
\hline 90 & 14 & 60 & 2.45 & 65 & 2.26 & 30611 & Yes \\
\hline 91 & 59 & 61 & 5.00 & 50 & 6.00 & 8000 & No \\
\hline 92 & 60 & 61 & 1.75 & 55 & 1.91 & 0 & Yes \\
\hline 93 & 61 & 62 & 8.70 & 50 & 10.44 & 31889 & No \\
\hline 94 & 60 & 62 & 10.00 & 65 & 9.23 & 57082 & Yes \\
\hline 95 & 18 & 62 & 10.50 & 55 & 11.45 & 18004 & No \\
\hline 96 & 62 & 63 & 6.70 & 50 & 8.04 & 6681 & No \\
\hline 97 & 62 & 64 & 11.20 & 65 & 10.34 & 31644 & Yes \\
\hline 98 & 63 & 64 & 4.60 & 50 & 5.52 & 0 & No \\
\hline 99 & 21 & 64 & 11.40 & 50 & 13.68 & 19753 & No \\
\hline 100 & 64 & 65 & 2.90 & 65 & 2.68 & 16150 & Yes \\
\hline 101 & 66 & 64 & 2.77 & 50 & 3.32 & 11685 & No \\
\hline 102 & 66 & 65 & 0.70 & 50 & 0.84 & 0 & No \\
\hline 103 & 34 & 66 & 3.50 & 50 & 4.20 & 4292 & No \\
\hline 104 & 34 & 67 & 1.90 & 55 & 2.07 & 10763 & Yes \\
\hline 105 & 65 & 67 & 3.00 & 65 & 2.77 & 6800 & Yes \\
\hline 106 & 68 & 67 & 6.20 & 65 & 5.72 & 35190 & Yes \\
\hline 107 & 36 & 68 & 2.40 & 50 & 2.88 & 0 & No \\
\hline 108 & 38 & 68 & 10.00 & 65 & 9.23 & 70736 & Yes \\
\hline 109 & 38 & 70 & 8.00 & 50 & 9.60 & 16641 & No \\
\hline 110 & 70 & 69 & 4.30 & 50 & 5.16 & 0 & No \\
\hline 111 & 70 & 71 & 10.50 & 50 & 12.60 & 3923 & No \\
\hline 112 & 68 & 71 & 6.80 & 50 & 8.16 & 26085 & No \\
\hline 113 & 71 & 72 & 4.70 & 50 & 5.64 & 15814 & No \\
\hline 114 & 67 & 72 & 7.40 & 55 & 8.07 & 0 & Yes \\
\hline
\end{tabular}




\begin{tabular}{|c|c|c|c|c|c|c|c|}
\hline 115 & 73 & 72 & 4.40 & 55 & 4.80 & 1030 & No \\
\hline 116 & 65 & 73 & 7.00 & 50 & 8.40 & 10246 & No \\
\hline 117 & 73 & 74 & 5.50 & 55 & 6.00 & 6749 & No \\
\hline 118 & 74 & 75 & 6.50 & 55 & 7.09 & 0 & No \\
\hline 119 & 62 & 75 & 12.20 & 45 & 16.27 & 9193 & No \\
\hline 120 & 75 & 76 & 7.00 & 55 & 7.64 & 15769 & $\mathrm{No}$ \\
\hline 121 & 77 & 76 & 5.50 & 50 & 6.60 & 0 & Yes \\
\hline 122 & 61 & 77 & 5.50 & 55 & 6.00 & 20523 & Yes \\
\hline 123 & 78 & 77 & 9.50 & 50 & 11.40 & 12451 & No \\
\hline 124 & 59 & 78 & 4.20 & 55 & 4.58 & 13496 & Yes \\
\hline 125 & 78 & 79 & 7.80 & 50 & 9.36 & 16108 & No \\
\hline 126 & 56 & 79 & 6.30 & 50 & 7.56 & 960 & $\mathrm{No}$ \\
\hline 127 & 53 & 79 & 12.30 & 50 & 14.76 & 16119 & No \\
\hline 128 & 51 & 80 & 3.00 & 50 & 3.60 & 0 & $\mathrm{No}$ \\
\hline 129 & 80 & 81 & 16.00 & 50 & 19.20 & 0 & No \\
\hline 130 & 81 & 82 & 4.70 & 55 & 5.13 & 13862 & Yes \\
\hline 131 & 79 & 82 & 6.00 & 50 & 7.20 & 7413 & No \\
\hline 132 & 82 & 83 & 4.80 & 55 & 5.24 & 7064 & Yes \\
\hline 133 & 78 & 83 & 7.80 & 55 & 8.51 & 20561 & Yes \\
\hline 134 & 83 & 84 & 1.70 & 45 & 2.27 & 19864 & Yes \\
\hline 135 & 76 & 84 & 11.60 & 55 & 12.65 & 5659 & $\mathrm{No}$ \\
\hline 136 & 83 & 85 & 8.80 & 55 & 9.60 & 36719 & Yes \\
\hline 137 & 85 & 86 & 12.30 & 50 & 14.76 & 12647 & No \\
\hline 138 & 84 & 86 & 15.00 & 50 & 18.00 & 30708 & No \\
\hline 139 & 86 & 87 & 6.50 & 50 & 7.80 & 1515 & No \\
\hline 140 & 76 & 87 & 13.40 & 55 & 14.62 & 31599 & Yes \\
\hline 141 & 75 & 88 & 7.80 & 50 & 9.36 & 21131 & No \\
\hline 142 & 88 & 87 & 4.50 & 50 & 5.40 & 4497 & $\mathrm{No}$ \\
\hline 143 & 87 & 89 & 10.00 & 50 & 12.00 & 2705 & No \\
\hline 144 & 88 & 90 & 8.30 & 50 & 9.96 & 9020 & No \\
\hline 145 & 90 & 89 & 2.20 & 50 & 2.64 & 0 & No \\
\hline 146 & 74 & 90 & 11.00 & 50 & 13.20 & 33265 & No \\
\hline 147 & 90 & 91 & 9.50 & 50 & 11.40 & 4796 & No \\
\hline 148 & 72 & 91 & 7.00 & 55 & 7.64 & 17776 & Yes \\
\hline 149 & 71 & 91 & 7.60 & 45 & 10.13 & 49043 & No \\
\hline 150 & 91 & 92 & 12.10 & 50 & 14.52 & 9165 & No \\
\hline 151 & 92 & 93 & 7.10 & 50 & 8.52 & 17262 & $\mathrm{No}$ \\
\hline 152 & 69 & 93 & 2.60 & 50 & 3.12 & 0 & Yes \\
\hline 153 & 93 & 94 & 13.70 & 55 & 14.95 & 49347 & Yes \\
\hline 154 & 92 & 95 & 11.10 & 50 & 13.32 & 18344 & No \\
\hline 155 & 95 & 94 & 12.50 & 55 & 13.64 & 17136 & No \\
\hline 156 & 95 & 96 & 5.90 & 55 & 6.44 & 5097 & No \\
\hline
\end{tabular}




\begin{tabular}{|c|c|c|c|c|c|c|c|}
\hline 157 & 91 & 96 & 7.30 & 55 & 7.96 & 1646 & Yes \\
\hline 158 & 94 & 97 & 1.90 & 50 & 2.28 & 12906 & Yes \\
\hline 159 & 97 & 98 & 10.90 & 55 & 11.89 & 26689 & No \\
\hline 160 & 98 & 99 & 2.40 & 55 & 2.62 & 8463 & No \\
\hline 161 & 99 & 100 & 1.50 & 55 & 1.64 & 29842 & No \\
\hline 162 & 98 & 101 & 9.90 & 50 & 11.88 & 21672 & No \\
\hline 163 & 100 & 101 & 6.10 & 55 & 6.65 & 22382 & Yes \\
\hline 164 & 96 & 101 & 13.80 & 55 & 15.05 & 38426 & Yes \\
\hline 165 & 101 & 102 & 14.10 & 55 & 15.38 & 11239 & Yes \\
\hline 166 & 89 & 102 & 14.60 & 50 & 17.52 & 26109 & No \\
\hline 167 & 87 & 102 & 13.30 & 55 & 14.51 & 51054 & Yes \\
\hline 168 & 103 & 102 & 7.30 & 55 & 7.96 & 148031 & Yes \\
\hline 169 & 87 & 104 & 10.70 & 50 & 12.84 & 104287 & No \\
\hline 170 & 104 & 103 & 4.10 & 50 & 4.92 & 2436 & No \\
\hline 171 & 85 & 105 & 4.00 & 55 & 4.36 & 156260 & Yes \\
\hline 172 & 105 & 104 & 13.60 & 50 & 16.32 & 3654 & No \\
\hline 173 & 105 & 106 & 9.00 & 55 & 9.82 & 21505 & Yes \\
\hline 174 & 106 & 107 & 2.80 & 55 & 3.05 & 87265 & Yes \\
\hline 175 & 107 & 104 & 8.70 & 50 & 10.44 & 11476 & No \\
\hline 176 & 107 & 103 & 11.10 & 55 & 12.11 & 39197 & Yes \\
\hline 177 & 106 & 108 & 5.30 & 50 & 6.36 & 0 & No \\
\hline 178 & 107 & 108 & 4.50 & 55 & 4.91 & 171805 & Yes \\
\hline 179 & 81 & 109 & 24.00 & 50 & 28.80 & 0 & No \\
\hline 180 & 108 & 109 & 7.00 & 65 & 6.46 & 0 & Yes \\
\hline 181 & 107 & 110 & 3.20 & 55 & 3.49 & 82840 & Yes \\
\hline 182 & 110 & 111 & 6.40 & 55 & 6.98 & 31875 & Yes \\
\hline 183 & 110 & 112 & 5.00 & 55 & 5.45 & 17728 & No \\
\hline 184 & 112 & 111 & 4.30 & 50 & 5.16 & 6781 & No \\
\hline 185 & 103 & 112 & 9.20 & 50 & 11.04 & 5396 & No \\
\hline 186 & 112 & 113 & 6.00 & 55 & 6.55 & 1224 & No \\
\hline 187 & 113 & 114 & 3.20 & 55 & 3.49 & 6911 & No \\
\hline 188 & 102 & 115 & 11.10 & 50 & 13.32 & 18980 & Yes \\
\hline 189 & 114 & 115 & 6.60 & 50 & 7.92 & 18396 & No \\
\hline 190 & 113 & 116 & 6.10 & 50 & 7.32 & 1636 & No \\
\hline 191 & 116 & 117 & 5.30 & 50 & 6.36 & 1495 & No \\
\hline 192 & 114 & 117 & 5.00 & 55 & 5.45 & 4904 & No \\
\hline 193 & 117 & 118 & 2.50 & 55 & 2.73 & 6471 & No \\
\hline 194 & 117 & 119 & 3.30 & 55 & 3.60 & 9147 & No \\
\hline 195 & 118 & 119 & 1.60 & 50 & 1.92 & 0 & No \\
\hline 196 & 118 & 120 & 5.30 & 50 & 6.36 & 41509 & No \\
\hline 197 & 115 & 121 & 3.60 & 50 & 4.32 & 7905 & Yes \\
\hline 198 & 121 & 120 & 2.60 & 50 & 3.12 & 0 & Yes \\
\hline
\end{tabular}




\begin{tabular}{|c|c|c|c|c|c|c|c|}
\hline 199 & 121 & 122 & 1.90 & 50 & 2.28 & 0 & No \\
\hline 200 & 122 & 120 & 1.90 & 50 & 2.28 & 0 & No \\
\hline 201 & 122 & 123 & 9.00 & 50 & 10.80 & 1193 & No \\
\hline 202 & 101 & 123 & 12.20 & 55 & 13.31 & 3069 & Yes \\
\hline 203 & 123 & 124 & 4.80 & 55 & 5.24 & 5934 & Yes \\
\hline 204 & 125 & 124 & 9.00 & 50 & 10.80 & 1400 & No \\
\hline 205 & 126 & 125 & 7.40 & 50 & 8.88 & 15616 & No \\
\hline 206 & 127 & 126 & 5.20 & 50 & 6.24 & 7993 & No \\
\hline 207 & 128 & 127 & 3.95 & 55 & 4.31 & 29665 & Yes \\
\hline 208 & 100 & 128 & 25.80 & 50 & 30.96 & 73101 & Yes \\
\hline 209 & 129 & 128 & 4.00 & 55 & 4.36 & 127895 & Yes \\
\hline 210 & 99 & 129 & 21.00 & 55 & 22.91 & 7935 & No \\
\hline 211 & 126 & 130 & 8.70 & 50 & 10.44 & 14612 & No \\
\hline 212 & 125 & 130 & 7.90 & 50 & 9.48 & 0 & No \\
\hline 213 & 130 & 131 & 1.80 & 50 & 2.16 & 0 & No \\
\hline 214 & 130 & 132 & 1.60 & 50 & 1.92 & 0 & No \\
\hline 215 & 132 & 131 & 1.20 & 50 & 1.44 & 0 & Yes \\
\hline 216 & 132 & 133 & 11.70 & 50 & 14.04 & 20218 & Yes \\
\hline 217 & 124 & 133 & 7.90 & 55 & 8.62 & 23066 & Yes \\
\hline 218 & 133 & 134 & 4.00 & 55 & 4.36 & 73126 & Yes \\
\hline 219 & 120 & 134 & 13.30 & 50 & 15.96 & 55858 & Yes \\
\hline 220 & 134 & 135 & 2.50 & 55 & 2.73 & 0 & Yes \\
\hline 221 & 119 & 135 & 12.20 & 55 & 13.31 & 10336 & No \\
\hline 222 & 135 & 136 & 6.00 & 45 & 8.00 & 7150 & Yes \\
\hline 223 & 119 & 136 & 10.20 & 50 & 12.24 & 4652 & No \\
\hline 224 & 136 & 137 & 3.00 & 45 & 4.00 & 0 & Yes \\
\hline 225 & 137 & 138 & 12.20 & 55 & 13.31 & 23563 & Yes \\
\hline 226 & 116 & 139 & 9.60 & 50 & 11.52 & 4594 & $\mathrm{No}$ \\
\hline 227 & 111 & 139 & 11.70 & 55 & 12.76 & 16390 & Yes \\
\hline 228 & 139 & 138 & 7.70 & 55 & 8.40 & 38090 & Yes \\
\hline 229 & 138 & 140 & 2.30 & 55 & 2.51 & 7735 & Yes \\
\hline 230 & 140 & 141 & 7.90 & 55 & 8.62 & 6214 & Yes \\
\hline 231 & 139 & 141 & 17.90 & 50 & 21.48 & 17725 & No \\
\hline 232 & 109 & 142 & 19.00 & 50 & 22.80 & 0 & No \\
\hline 233 & 108 & 142 & 30.00 & 50 & 36.00 & 0 & No \\
\hline 234 & 142 & 143 & 6.20 & 50 & 7.44 & 0 & No \\
\hline 235 & 143 & 141 & 5.70 & 50 & 6.84 & 46022 & Yes \\
\hline 236 & 141 & 144 & 6.30 & 50 & 7.56 & 5436 & No \\
\hline 237 & 140 & 145 & 6.10 & 55 & 6.65 & 3270 & Yes \\
\hline 238 & 144 & 145 & 7.00 & 50 & 8.40 & 10580 & No \\
\hline 239 & 145 & 146 & 8.90 & 50 & 10.68 & 26237 & No \\
\hline 240 & 146 & 147 & 3.70 & 50 & 4.44 & 0 & No \\
\hline
\end{tabular}




\begin{tabular}{|c|c|c|c|c|c|c|c|}
\hline 241 & 137 & 147 & 6.90 & 55 & 7.53 & 0 & No \\
\hline 242 & 147 & 148 & 10.50 & 50 & 12.60 & 3829 & No \\
\hline 243 & 148 & 149 & 3.00 & 50 & 3.60 & 2545 & No \\
\hline 244 & 135 & 150 & 4.00 & 55 & 4.36 & 2629 & No \\
\hline 245 & 134 & 150 & 3.10 & 55 & 3.38 & 7161 & Yes \\
\hline 246 & 150 & 149 & 3.10 & 55 & 3.38 & 4315 & Yes \\
\hline 247 & 133 & 149 & 9.40 & 50 & 11.28 & 40281 & No \\
\hline 248 & 127 & 151 & 17.60 & 55 & 19.20 & 17005 & Yes \\
\hline 249 & 131 & 151 & 11.50 & 50 & 13.80 & 0 & Yes \\
\hline 250 & 132 & 152 & 11.50 & 50 & 13.80 & 11964 & No \\
\hline 251 & 151 & 152 & 6.60 & 50 & 7.92 & 0 & No \\
\hline 252 & 151 & 153 & 3.10 & 55 & 3.38 & 0 & No \\
\hline 253 & 153 & 154 & 14.10 & 55 & 15.38 & 0 & No \\
\hline 254 & 152 & 154 & 11.70 & 50 & 14.04 & 0 & No \\
\hline 255 & 154 & 155 & 1.20 & 55 & 1.31 & 0 & No \\
\hline 256 & 149 & 155 & 17.80 & 55 & 19.42 & 41432 & Yes \\
\hline 257 & 155 & 156 & 6.40 & 55 & 6.98 & 0 & No \\
\hline 258 & 156 & 157 & 14.90 & 50 & 17.88 & 0 & No \\
\hline 259 & 148 & 157 & 13.70 & 50 & 16.44 & 0 & No \\
\hline 260 & 147 & 157 & 12.20 & 55 & 13.31 & 0 & No \\
\hline 261 & 157 & 158 & 8.20 & 50 & 9.84 & 0 & No \\
\hline 262 & 146 & 158 & 5.10 & 50 & 6.12 & 0 & No \\
\hline 263 & 158 & 159 & 8.90 & 50 & 10.68 & 0 & No \\
\hline 264 & 145 & 159 & 6.30 & 55 & 6.87 & 0 & Yes \\
\hline 265 & 144 & 160 & 5.70 & 50 & 6.84 & 0 & No \\
\hline 266 & 159 & 160 & 5.80 & 50 & 6.96 & 0 & No \\
\hline 267 & 143 & 161 & 21.80 & 50 & 26.16 & 0 & No \\
\hline 268 & 161 & 162 & 2.00 & 50 & 2.40 & 0 & No \\
\hline 269 & 162 & 163 & 13.00 & 50 & 15.60 & 0 & No \\
\hline 270 & 163 & 164 & 9.00 & 55 & 9.82 & 0 & No \\
\hline 271 & 164 & 165 & 12.00 & 55 & 13.09 & 0 & No \\
\hline 272 & 162 & 166 & 6.70 & 65 & 6.18 & 0 & Yes \\
\hline 273 & 161 & 166 & 7.00 & 45 & 9.33 & 0 & No \\
\hline 274 & 166 & 165 & 4.50 & 45 & 6.00 & 0 & No \\
\hline 275 & 166 & 167 & 9.00 & 65 & 8.31 & 0 & Yes \\
\hline 276 & 160 & 167 & 13.40 & 50 & 16.08 & 0 & No \\
\hline 277 & 159 & 167 & 11.40 & 55 & 12.44 & 0 & Yes \\
\hline 278 & 167 & 168 & 2.65 & 45 & 3.53 & 0 & Yes \\
\hline 279 & 165 & 168 & 2.00 & 45 & 2.67 & 0 & No \\
\hline 280 & 167 & 169 & 4.30 & 65 & 3.97 & 0 & Yes \\
\hline 281 & 168 & 170 & 4.50 & 45 & 6.00 & 0 & No \\
\hline 282 & 169 & 171 & 2.30 & 45 & 3.07 & 0 & No \\
\hline
\end{tabular}




\begin{tabular}{|l|c|c|c|c|c|c|c|}
\hline 283 & 171 & 170 & 1.00 & 45 & 1.33 & 0 & No \\
\hline 284 & 171 & 172 & 7.80 & 50 & 9.36 & 0 & No \\
\hline 285 & 169 & 172 & 7.30 & 65 & 6.74 & 0 & Yes \\
\hline 286 & 173 & 169 & 3.40 & 35 & 5.83 & 0 & No \\
\hline 287 & 158 & 173 & 11.80 & 50 & 14.16 & 0 & No \\
\hline 288 & 173 & 174 & 10.40 & 50 & 12.48 & 0 & No \\
\hline 289 & 157 & 174 & 7.30 & 55 & 7.96 & 0 & No \\
\hline 290 & 156 & 174 & 14.80 & 55 & 16.15 & 0 & No \\
\hline 291 & 174 & 175 & 5.00 & 55 & 5.45 & 0 & No \\
\hline 292 & 172 & 175 & 4.25 & 50 & 5.10 & 0 & Yes \\
\hline 293 & 170 & 176 & 11.70 & 45 & 15.60 & 0 & No \\
\hline 294 & 175 & 176 & 5.10 & 55 & 5.56 & 0 & No \\
\hline 295 & 175 & 177 & 16.10 & 50 & 19.32 & 0 & No \\
\hline 296 & 175 & 178 & 14.50 & 65 & 13.38 & 0 & Yes \\
\hline 297 & 176 & 183 & 14.50 & 55 & 15.82 & 0 & No \\
\hline 298 & 178 & 183 & 3.90 & 50 & 4.68 & 0 & No \\
\hline 299 & 177 & 178 & 5.40 & 50 & 6.48 & 0 & No \\
\hline 300 & 155 & 179 & 5.80 & 55 & 6.33 & 0 & Yes \\
\hline 301 & 179 & 180 & 10.70 & 55 & 11.67 & 0 & Yes \\
\hline 302 & 177 & 180 & 5.60 & 50 & 6.72 & 0 & No \\
\hline 303 & 180 & 181 & 2.40 & 55 & 2.62 & 0 & Yes \\
\hline 304 & 178 & 181 & 4.00 & 65 & 3.69 & 0 & Yes \\
\hline 305 & 181 & 182 & 3.70 & 55 & 4.04 & 0 & Yes \\
\hline 306 & 183 & 182 & 2.60 & 55 & 2.84 & 0 & No \\
\hline 307 & 182 & 184 & 4.70 & 55 & 5.13 & 0 & Yes \\
\hline 308 & 97 & 129 & 20.00 & 55 & 21.82 & 0 & Yes \\
\hline 309 & 39 & 69 & 8.00 & 55 & 8.73 & 0 & Yes \\
\hline
\end{tabular}


APPENDIX B: LINK IDs

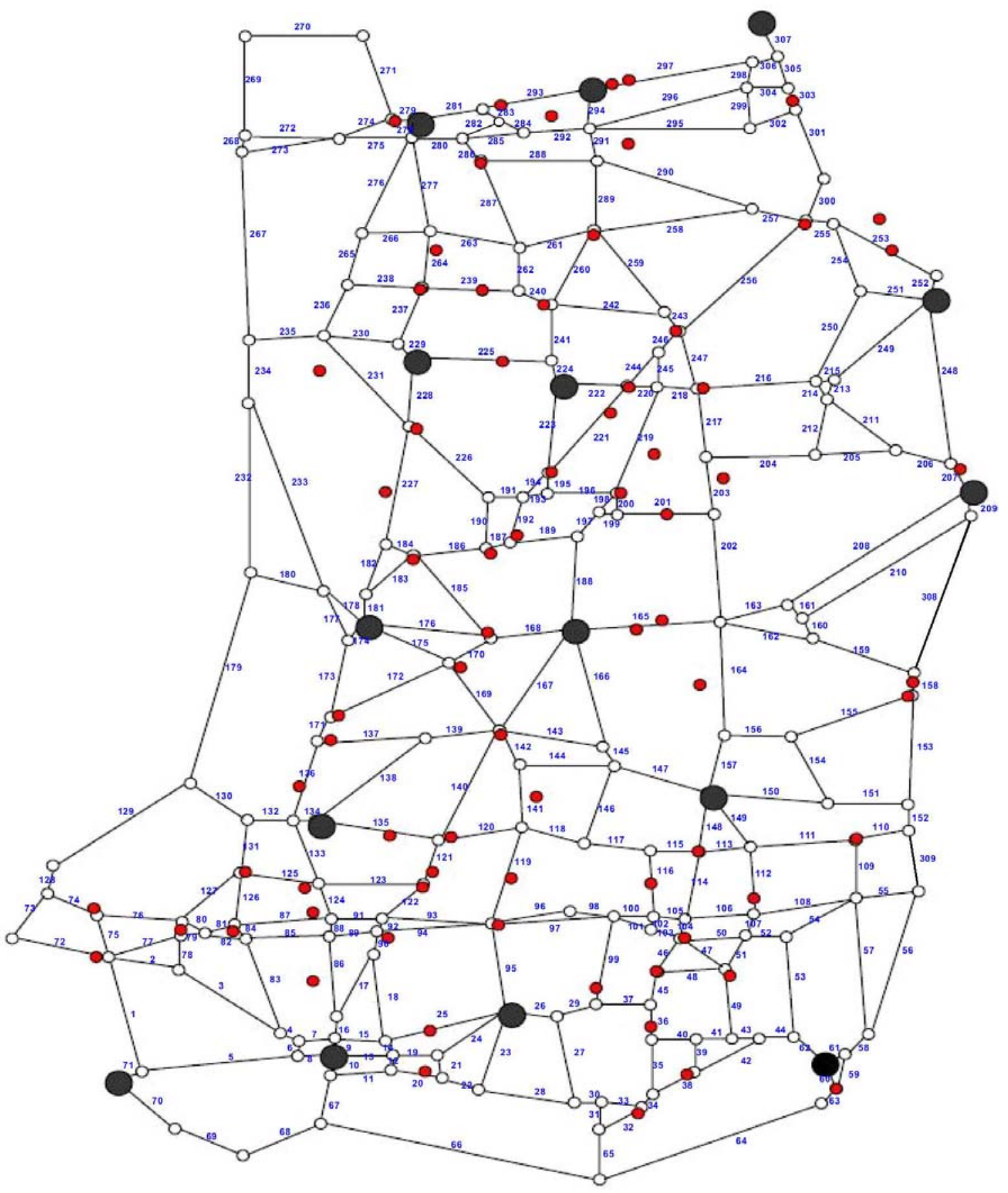




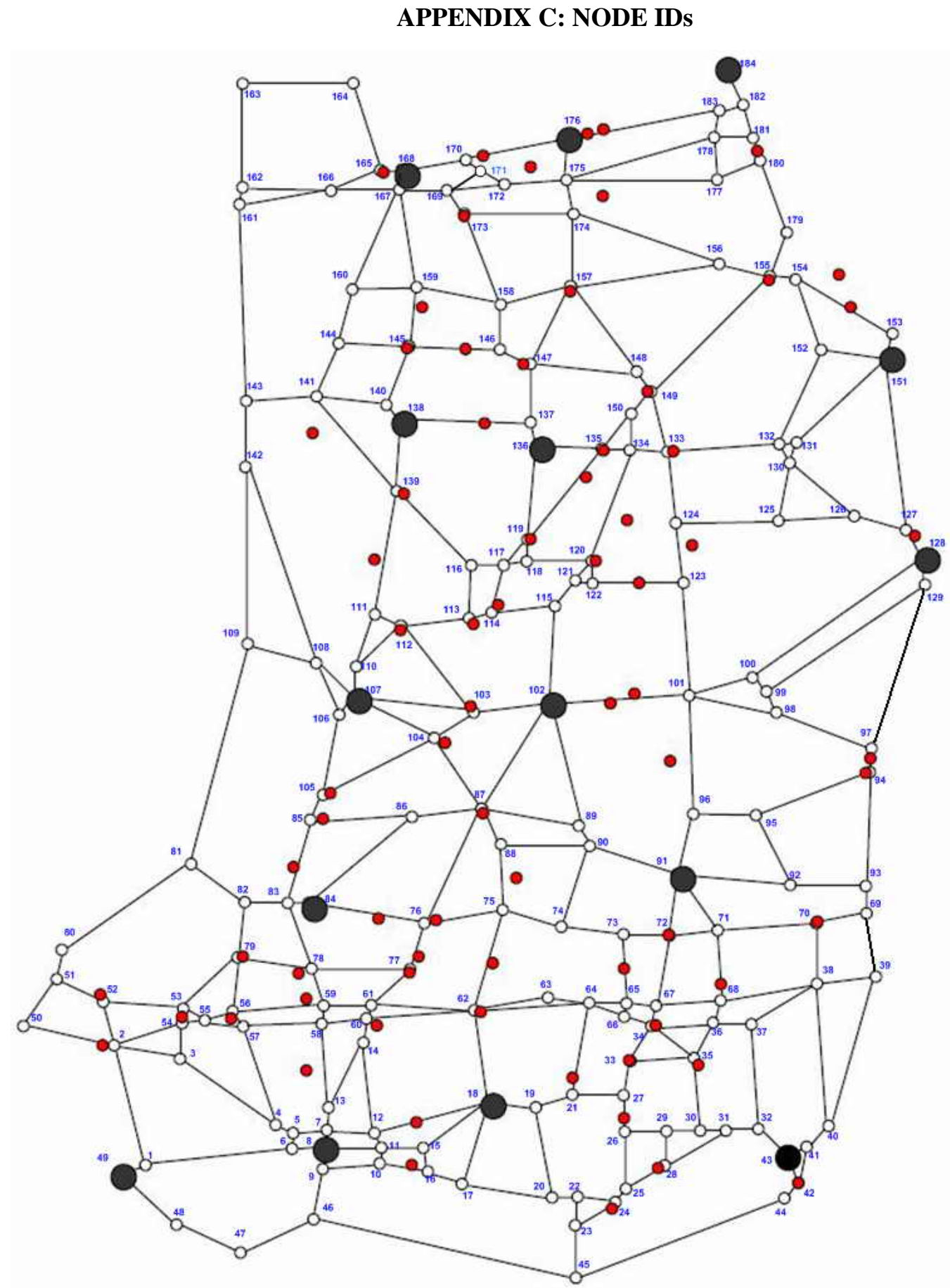


APPENDIX D: POPULATION DATA

\begin{tabular}{|c|c|c|c|c|c|c|c|c|c|}
\hline ID & City / Town & $\begin{array}{c}\text { Link } \\
1\end{array}$ & $\begin{array}{c}\text { Link } \\
2\end{array}$ & $\begin{array}{c}\text { Link } \\
3\end{array}$ & $\begin{array}{c}\text { Link } \\
4\end{array}$ & $\begin{array}{c}\text { Link } \\
5\end{array}$ & $\begin{array}{l}\text { Link } \\
6\end{array}$ & $\begin{array}{l}\text { Additional } \\
\text { assignment } \\
\text { in INDOT- } \\
\text { Maintained } \\
\text { Network }\end{array}$ & Population \\
\hline 1 & Cynthiana & 81 & 84 & 87 & 126 & & & 82 & 693 \\
\hline 2 & Griffin & 74 & 75 & 76 & & & & & 160 \\
\hline 3 & Mt. Vernon & 71 & 70 & & & & & & 7478 \\
\hline 4 & $\begin{array}{c}\text { New } \\
\text { Harmony }\end{array}$ & 1 & 2 & 72 & 75 & 77 & & 74 & 916 \\
\hline 5 & Poseyville & 77 & 78 & 79 & & & & 80 & 1187 \\
\hline 6 & Darmstadt & 86 & & & & & & & 1313 \\
\hline 7 & Evansville & 8 & 9 & 10 & 13 & & & & 121582 \\
\hline 8 & Boonville & 23 & 24 & 25 & 26 & 95 & & & 6834 \\
\hline 9 & Chandler & 25 & & & & & & & 3094 \\
\hline 10 & Elberfeld & 94 & & & & & & & 636 \\
\hline 11 & Lynnville & 93 & 94 & 95 & 96 & 97 & 119 & & 781 \\
\hline 12 & Newburgh & 20 & & & & & & & 3088 \\
\hline 13 & Tennyson & 99 & & & & & & 37 & 290 \\
\hline 14 & Chrisney & 36 & & & & & & & 544 \\
\hline 15 & Dale & 46 & 47 & 50 & 103 & 104 & & & 1568 \\
\hline 16 & Genrtyville & 45 & 46 & 48 & & & & & 262 \\
\hline 17 & Grandview & 38 & 39 & 42 & & & & 35 & 696 \\
\hline 18 & Rockport & 32 & 33 & 34 & & & & & 2160 \\
\hline 19 & Santa Claus & 49 & & & & & & 46 & 2041 \\
\hline 20 & Tell City & 60 & 61 & 62 & & & & & 7845 \\
\hline 21 & Cannelton & 59 & 60 & 63 & & & & & 1209 \\
\hline 22 & Troy & 44 & 53 & 62 & & & & 61 & 392 \\
\hline 23 & Fort Branch & 125 & & & & & & 124 & 2320 \\
\hline 24 & Francisco & 135 & & & & & & 121 & 543 \\
\hline 25 & Haubstadt & 87 & & & & & & 124 & 1529 \\
\hline 26 & Hazleton & 137 & & & & & & 171 & 288 \\
\hline 27 & Mackey & 121 & 122 & 123 & & & & & 142 \\
\hline 28 & Oakland & 120 & & & & & & 140 & 2588 \\
\hline 29 & Owensville & 125 & 126 & 127 & 131 & & & 132 & 1322 \\
\hline
\end{tabular}




\begin{tabular}{|c|c|c|c|c|c|c|c|c|c|}
\hline 30 & Patoka & 136 & & & & & & & 749 \\
\hline 31 & Princeton & 134 & 135 & 138 & & & & & 8175 \\
\hline 32 & Somerville & 121 & & & & & & & 312 \\
\hline 33 & Petersburg & 139 & 140 & 142 & 143 & 167 & 169 & & 2570 \\
\hline 34 & Spurgeon & 119 & & & & & & 97 & 227 \\
\hline 35 & Winslow & 141 & & & & & & 140 & 881 \\
\hline 36 & Birdseye & 109 & 110 & 111 & & & & 152 & 465 \\
\hline 37 & Ferdinand & 112 & & & & & & 108 & 2277 \\
\hline 38 & Holland & 116 & & & & & & 105 & 695 \\
\hline 39 & Huntingburg & 113 & 114 & 115 & 148 & & & & 5598 \\
\hline 40 & Jasper & 147 & 148 & 149 & 150 & 157 & & & 12100 \\
\hline 41 & Bicknell & 186 & 187 & 190 & & & & 188 & 3378 \\
\hline 42 & Bruceville & 183 & 184 & 185 & 186 & & & 182 & 469 \\
\hline 43 & Decker & 171 & 172 & 173 & & & & & 283 \\
\hline 44 & Edwardsport & 192 & & & & & & 197 & 363 \\
\hline 45 & Monroe city & 169 & & & & & & 176 & 548 \\
\hline 46 & Oaktown & 227 & & & & & & & 633 \\
\hline 47 & Sandborn & 194 & 195 & 221 & 223 & & & 219 & 451 \\
\hline 48 & Vincennes & 174 & 175 & 176 & 178 & 181 & & & 18701 \\
\hline 49 & Wheatland & 168 & 170 & 176 & 185 & & & & 504 \\
\hline 50 & Alfordville & 164 & & & & & & & 112 \\
\hline 51 & Cannelburg & 165 & & & & & & & 140 \\
\hline 52 & Elnora & 196 & 198 & 200 & 219 & & & & 721 \\
\hline 53 & Montgomery & 165 & & & & & & & 368 \\
\hline 54 & Odon & 201 & & & & & & 203 & 1376 \\
\hline 55 & Plainville & 188 & 189 & 197 & & & & & 513 \\
\hline 56 & Washington & 165 & 166 & 167 & 168 & 188 & & & 11380 \\
\hline 57 & Crane & 203 & & & & & & & 203 \\
\hline 58 & Shoals & 160 & 161 & 210 & & & & 208 & 807 \\
\hline 59 & Loogootee & 162 & 163 & 164 & 165 & 202 & & & 2741 \\
\hline 60 & French Lick & 153 & 155 & 158 & & & & & 1941 \\
\hline 61 & $\begin{array}{c}\text { West Baden } \\
\text { Springs }\end{array}$ & 158 & & & & & & & 618 \\
\hline 62 & Bedford & 207 & 208 & 209 & & & & & 13768 \\
\hline 63 & Oolitic & 207 & & & & & & & 1152 \\
\hline 64 & Bloomington & 248 & 249 & 251 & 252 & & & & 69291 \\
\hline 65 & Stinesville & 253 & & & & & & 256 & 194 \\
\hline 66 & Ellettsville & 253 & & & & & & 249 & 5078 \\
\hline 67 & Bloomfield & 216 & 217 & 218 & 247 & & & & 2542 \\
\hline 68 & Jasonville & 240 & & & & & & 237 & 2490 \\
\hline 69 & Linton & 222 & 223 & 224 & & & & & 5774 \\
\hline 70 & Lyons & 221 & & & & & & 219 & 748 \\
\hline
\end{tabular}




\begin{tabular}{|c|c|c|c|c|c|c|c|c|}
\hline 71 & Newberry & 219 & & & & & & 206 \\
\hline 72 & Switz & 220 & 221 & 222 & 244 & & & 311 \\
\hline 73 & Worthington & 243 & 246 & 247 & 256 & & & 1481 \\
\hline 74 & Carlisle & 226 & 227 & 228 & 231 & & & 2660 \\
\hline 75 & Dugger & 225 & & & & & & 955 \\
\hline 76 & Farmersburg & 264 & & & & & & 1180 \\
\hline 77 & Hymera & 239 & & & & & 264 & 833 \\
\hline 78 & Merom & 231 & & & & & 235 & 294 \\
\hline 79 & Shelburn & 237 & 238 & 239 & 264 & & & 1268 \\
\hline 80 & Sullivan & 225 & 228 & 229 & & & & 4617 \\
\hline 81 & Riley & 286 & 287 & 288 & & & 285 & 160 \\
\hline 82 & Seelyville & 293 & & & & & 285 & 1182 \\
\hline 83 & Terra Haute & 278 & 279 & 281 & & & & 59614 \\
\hline 84 & $\begin{array}{l}\text { West Terra } \\
\text { Haute }\end{array}$ & 271 & 274 & 279 & & & 278 & 2330 \\
\hline 85 & Brazil & 293 & 294 & 297 & & & 296 & 8188 \\
\hline 86 & Center Point & 295 & & & & & 296 & 292 \\
\hline 87 & Clay city & 258 & 259 & 260 & 261 & 289 & 296 & 1019 \\
\hline 88 & Harmony & 297 & & & & & 296 & 589 \\
\hline 89 & Knightsville & 297 & & & & & 296 & 624 \\
\hline 90 & Staunton & 293 & & & & & 292 & 550 \\
\hline 91 & Spencer & 255 & 256 & 257 & 300 & & & 2508 \\
\hline 92 & Cloverdale & 303 & & & & & & 2243 \\
\hline 93 & Greencastle & 307 & & & & & & 9880 \\
\hline
\end{tabular}


APPENDIX E: POPULATION CENTER IDs

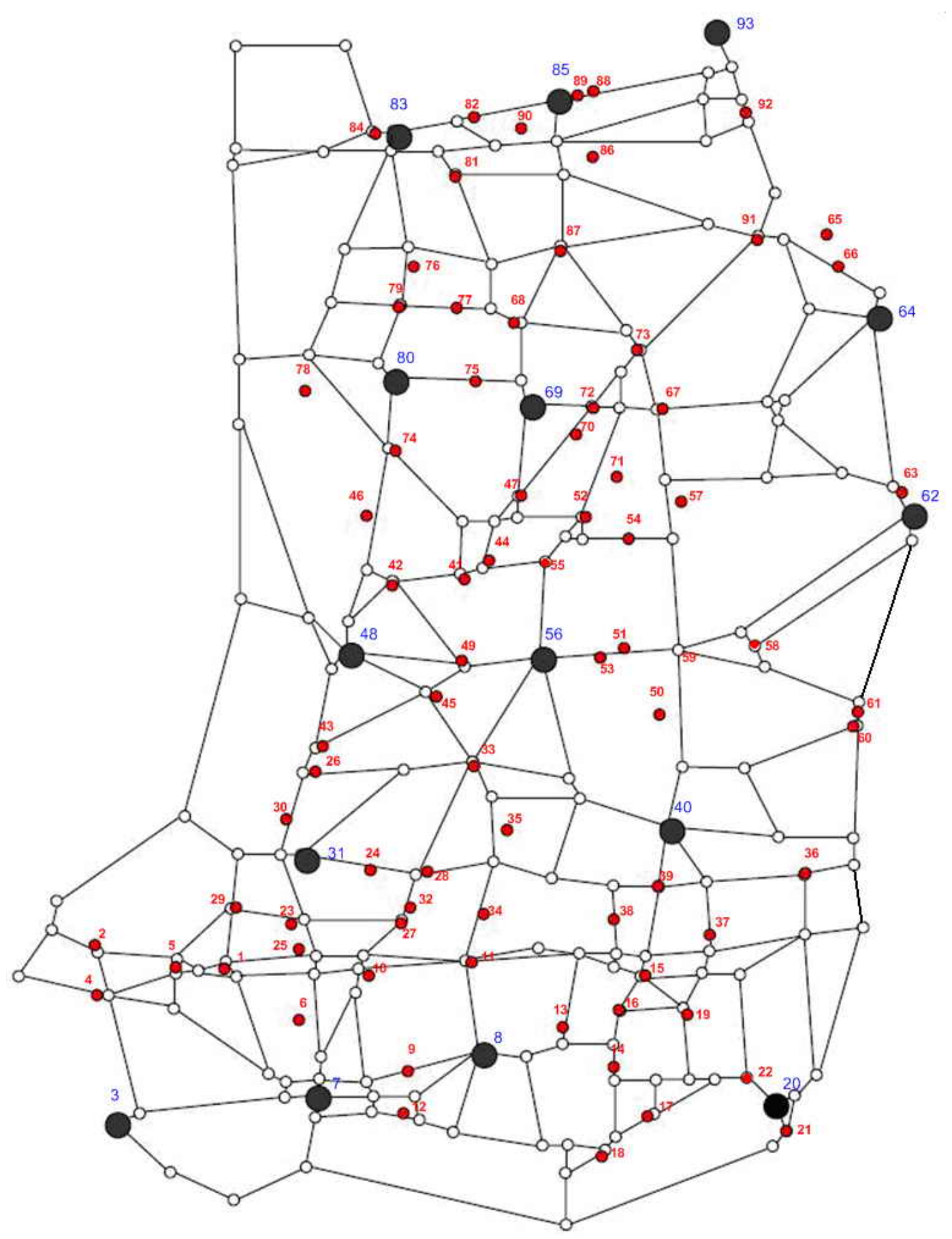


APPENDIX F: COMPUTATIONAL RESULTS

\begin{tabular}{|c|c|c|c|c|c|c|}
\hline Network & $\begin{array}{c}\text { Time } \\
\text { weight }\end{array}$ & $\begin{array}{c}\text { Total } \\
\text { travel } \\
\text { time } \\
\text { (min) }\end{array}$ & $\begin{array}{c}\text { Population } \\
\text { weight }\end{array}$ & $\begin{array}{c}\text { Population } \\
\text { covered } \\
\text { (persons) }\end{array}$ & $\begin{array}{c}\text { Budget } \\
\text { (million } \\
\text { sq. feet) }\end{array}$ & $\begin{array}{c}\text { Optimality } \\
\text { gap }\end{array}$ \\
\hline $\begin{array}{c}\text { INDOT- } \\
\text { Maintain. }\end{array}$ & 0.975 & 1747.8 & 0.025 & 437448 & 1.67 & $2 \%$ \\
\hline $\begin{array}{c}\text { INDOT- } \\
\text { Maintain. }\end{array}$ & 0.983 & 1707.0 & 0.018 & 437311 & 1.67 & $2 \%$ \\
\hline $\begin{array}{c}\text { INDOT- } \\
\text { Maintain. }\end{array}$ & 0.990 & 1695.3 & 0.010 & 437311 & 1.67 & $2 \%$ \\
\hline $\begin{array}{c}\text { INDOT- } \\
\text { Maintain. }\end{array}$ & 0.995 & 1695.3 & 0.005 & 437311 & 1.67 & $2 \%$ \\
\hline $\begin{array}{c}\text { INDOT- } \\
\text { Maintain. }\end{array}$ & 0.999 & 1695.3 & 0.001 & 432503 & 1.67 & $2 \%$ \\
\hline $\begin{array}{c}\text { INDOT- } \\
\text { Maintain. }\end{array}$ & 0.975 & 1735.3 & 0.025 & 447703 & 2.00 & $2 \%$ \\
\hline $\begin{array}{c}\text { INDOT- } \\
\text { Maintain. }\end{array}$ & 0.983 & 1679.2 & 0.018 & 447703 & 2.00 & $2 \%$ \\
\hline $\begin{array}{c}\text { INDOT- } \\
\text { Maintain. }\end{array}$ & 0.990 & 1590.5 & 0.010 & 435479 & 2.00 & $2 \%$ \\
\hline $\begin{array}{c}\text { INDOT- } \\
\text { Maintain. }\end{array}$ & 0.995 & 1590.5 & 0.005 & 435479 & 2.00 & $2 \%$ \\
\hline $\begin{array}{c}\text { INDOT- } \\
\text { Maintain. }\end{array}$ & 0.999 & 1587.0 & 0.001 & 433923 & 2.00 & $0 \%$ \\
\hline $\begin{array}{c}\text { INDOT- } \\
\text { Maintain. }\end{array}$ & 0.975 & 1719.7 & 0.025 & 449031 & 2.30 & $2 \%$ \\
\hline $\begin{array}{c}\text { INDOT- } \\
\text { Maintain. }\end{array}$ & 0.983 & 1637.7 & 0.018 & 449031 & 2.30 & $2 \%$ \\
\hline $\begin{array}{c}\text { INDOT- } \\
\text { Maintain. }\end{array}$ & 0.990 & 1622.9 & 0.010 & 449031 & 2.30 & $2 \%$ \\
\hline $\begin{array}{c}\text { INDOT- } \\
\text { Maintain. }\end{array}$ & 0.995 & 1622.9 & 0.005 & 443995 & 2.30 & $0 \%$ \\
\hline INDOT- & 0.999 & 1588.4 & 0.001 & 435479 & 2.30 & $0 \%$ \\
\hline
\end{tabular}




\begin{tabular}{|c|c|c|c|c|c|c|}
\hline aintain. & & & & & & \\
\hline $\begin{array}{l}\text { INDOT- } \\
\text { Maintain. }\end{array}$ & 0.900 & 1653.5 & 0.100 & 452052 & 2.67 & $0 \%$ \\
\hline $\begin{array}{l}\text { INDOT- } \\
\text { Maintain. }\end{array}$ & 0.950 & 1653.5 & 0.050 & 452052 & 2.67 & $0 \%$ \\
\hline $\begin{array}{l}\text { INDOT- } \\
\text { Maintain. }\end{array}$ & 0.975 & 1653.5 & 0.025 & 452052 & 2.67 & $0 \%$ \\
\hline $\begin{array}{l}\text { INDOT- } \\
\text { Maintain. }\end{array}$ & 0.983 & 1653.5 & 0.018 & 452052 & 2.67 & $0 \%$ \\
\hline $\begin{array}{l}\text { INDOT- } \\
\text { Maintain. }\end{array}$ & 0.990 & 1621.0 & 0.010 & 449031 & 2.67 & $0 \%$ \\
\hline $\begin{array}{l}\text { INDOT- } \\
\text { Maintain. }\end{array}$ & 0.995 & 1621.0 & 0.005 & 449031 & 2.67 & $0 \%$ \\
\hline $\begin{array}{l}\text { INDOT- } \\
\text { Maintain. }\end{array}$ & 0.999 & 1588.4 & 0.001 & 435479 & 2.67 & $0 \%$ \\
\hline $\begin{array}{l}\text { INDOT- } \\
\text { Maintain. }\end{array}$ & 0.900 & 1653.5 & 0.100 & 452052 & 3.00 & $2 \%$ \\
\hline $\begin{array}{l}\text { INDOT- } \\
\text { Maintain. }\end{array}$ & 0.950 & 1653.5 & 0.050 & 452052 & 3.00 & $0 \%$ \\
\hline $\begin{array}{l}\text { INDOT- } \\
\text { Maintain. }\end{array}$ & 0.975 & 1653.5 & 0.025 & 452052 & 3.00 & $0 \%$ \\
\hline $\begin{array}{l}\text { INDOT- } \\
\text { Maintain. }\end{array}$ & 0.983 & 1653.5 & 0.018 & 452052 & 3.00 & $0 \%$ \\
\hline $\begin{array}{l}\text { INDOT- } \\
\text { Maintain. }\end{array}$ & 0.990 & 1621.0 & 0.010 & 449031 & 3.00 & $0 \%$ \\
\hline $\begin{array}{l}\text { INDOT- } \\
\text { Maintain. }\end{array}$ & 0.995 & 1621.0 & 0.005 & 449031 & 3.00 & $0 \%$ \\
\hline $\begin{array}{l}\text { INDOT- } \\
\text { Maintain. }\end{array}$ & 0.999 & 1588.4 & 0.001 & 435479 & 3.00 & $0 \%$ \\
\hline $\begin{array}{l}\text { INDOT- } \\
\text { Maintain. }\end{array}$ & 0.900 & 1653.5 & 0.100 & 452052 & 3.33 & $2 \%$ \\
\hline $\begin{array}{l}\text { INDOT- } \\
\text { Maintain. }\end{array}$ & 0.950 & 1653.5 & 0.050 & 452052 & 3.33 & $0 \%$ \\
\hline $\begin{array}{l}\text { INDOT- } \\
\text { Maintain. }\end{array}$ & 0.975 & 1653.5 & 0.025 & 452052 & 3.33 & $0 \%$ \\
\hline $\begin{array}{l}\text { INDOT- } \\
\text { Maintain. }\end{array}$ & 0.983 & 1653.5 & 0.018 & 452052 & 3.33 & $0 \%$ \\
\hline $\begin{array}{l}\text { INDOT- } \\
\text { Maintain. }\end{array}$ & 0.990 & 1621.0 & 0.010 & 449031 & 3.33 & $0 \%$ \\
\hline $\begin{array}{l}\text { INDOT- } \\
\text { Maintain. }\end{array}$ & 0.995 & 1621.0 & 0.005 & 449031 & 3.33 & $0 \%$ \\
\hline $\begin{array}{l}\text { INDOT- } \\
\text { Maintain. }\end{array}$ & 0.999 & 1588.4 & 0.001 & 435479 & 3.33 & $0 \%$ \\
\hline
\end{tabular}




\begin{tabular}{|l|l|l|l|l|l|l|}
\cline { 6 - 7 } Complete & 0.999 & 1662.63 & 0.001 & 408422 & 1.67 & NA \\
\hline Complete & 0.990 & 1685.59 & 0.010 & 410802 & 1.67 & NA \\
\hline Complete & 0.950 & 1686.69 & 0.050 & 410802 & 1.67 & NA \\
\hline Complete & 0.900 & 1715.19 & 0.100 & 411855 & 1.67 & NA \\
\hline Complete & 0.999 & 1391.75 & 0.001 & 413091 & 2.00 & NA \\
\hline Complete & 0.990 & 1466.27 & 0.010 & 429665 & 2.00 & NA \\
\hline Complete & 0.950 & 1646.53 & 0.050 & 434609 & 2.00 & NA \\
\hline Complete & 0.900 & 1755.28 & 0.100 & 434461 & 2.00 & NA \\
\hline Complete & 0.999 & 1346.02 & 0.001 & 427829 & 2.33 & NA \\
\hline Complete & 0.990 & 1398.75 & 0.010 & 445473 & 2.33 & NA \\
\hline Complete & 0.950 & 1584.67 & 0.050 & 449826 & 2.33 & NA \\
\hline Complete & 0.900 & 1778.19 & 0.100 & 450736 & 2.33 & NA \\
\hline Complete & 0.999 & 1337.23 & 0.001 & 435301 & 2.67 & NA \\
\hline Complete & 0.990 & 1425.29 & 0.010 & 450589 & 2.67 & NA \\
\hline Complete & 0.950 & 1599.52 & 0.050 & 453614 & 2.67 & NA \\
\hline Complete & 0.900 & 1695.34 & 0.100 & 455026 & 2.67 & NA \\
\hline Complete & 0.999 & 1328.15 & 0.001 & 436562 & 3.00 & NA \\
\hline Complete & 0.990 & 1411.76 & 0.010 & 451015 & 3.00 & NA \\
\hline Complete & 0.950 & 1592.24 & 0.050 & 455519 & 3.00 & NA \\
\hline Complete & 0.900 & 1689.16 & 0.100 & 456991 & 3.00 & NA \\
\hline Complete & 0.999 & 1323.77 & 0.001 & 436682 & 3.33 & NA \\
\hline Complete & 0.990 & 1407.76 & 0.010 & 452018 & 3.33 & NA \\
\hline Complete & 0.950 & 1516.12 & 0.050 & 456048 & 3.33 & NA \\
\hline Complete & 0.900 & 1614.49 & 0.100 & 457661 & 3.33 & NA \\
\hline
\end{tabular}




\section{APPENDIX G: THE GAMS/CPLEX RESOURCES}

Official site $\quad:$ http://www.gams.com/

GAMS User Guides: http://www.gams.com/docs/gams/GAMSUsersGuide.pdf

http://www.gams.com/docs/gams/Tutorial.pdf

CPLEX User Guide : http://www.gams.com/solvers/cplex.pdf 


\section{APPENDIX H: THE GAMS/CPLEX CODE FOR DYNAMIC REROUTING}

\section{\$offlisting}

file RunIDfile /RunIDfile.itm/ , AssemblyID /OutAssemblyIDDR.txt/, Paths /OutPathsDR.txt/, Warnings /OutWarningsDR.txt/;

Set i "Nodes" / $1 * 184 /$;

*Undirected arcs are 307, the directed arcs doubled=> 614

Set j "Directed Arcs" / $1 * 618 /$;

Set $\quad \mathrm{k} \quad$ "Undirected Arcs" /1*309/;

set l "Commodities/Routes" /1*33/;

Scalars

ResponderRouteIndex "Selection of O-D pair that we are solving for", WarningIndex "Warning Index" /0/,

RunID - "Run ID"

parameters

$\mathrm{y}(\mathrm{k}) \quad$ "If undirected link $\mathrm{k}$ is has been retrofitted or not (0 or 1$)$ ",

$\mathrm{a}(\mathrm{i}, \mathrm{j}) \quad$ "Node-arc incidence Matrix: Node i is related to arck $\mathrm{j}$ ",

$\mathrm{t}(\mathrm{j}) \quad$ "Travel time of link $\mathrm{j}$ in minutes"

LinkStatus(k) "Link Status: If Undirected link k is usable"

LinkVerification(k) "Link Verification: Links that have been verified" ,

be(k) $\quad$ "If Bridge Exists in Undirected link k"

Terminal(l,i) "If node $\mathrm{i}$ is a Terminal for responder route l: origin (+1) or a destination (-1)",

$\mathrm{DU}(\mathrm{j}, \mathrm{k}) \quad$ "If directed link $\mathrm{j}$ belongs to undirected link k"

SingleTerminal(i) "Single Terminal",

LocalPath(k) "Undirected route",

NetSelectedLink(k) "If this link is selected in the final network",

RouteVerificationIndexL "If routing for local OD-Pair has been verified" /0/,

RouteFeasibilityIndexL "If routing for local OD-Pair is feasible" /1/;

** LinkStatus and LinkVerification have to be initialized before a series of execution.

** LinkStatus $(\mathrm{k})=1$ and LinkVerification $(\mathrm{k})=0$

Sinclude ArcNodeIncidence.inc

\$include TravelTime.inc

\$include BridgeExists.inc

Sinclude LinkStatus.inc

\$include LinkVerification.inc

\$include RunIDfile.itm

\$include DirectUndirected.inc

Sinclude Terminal.inc

Positive variables

$\mathrm{x}(\mathrm{j}) \quad$ "If the responder use link j";

free variables

TotalTravelTime "Objective Variable: Total Travel Times"

equations

TimeObjective "Multiple Objectives",

ConservationOfFlow(i) "Conservation of flow for all nodes i (and all responder routes)",

Capacity(j) "Link is assumed to be accesible only if it is not confirmed that the link is not accesible"; 
x.up(j)=1;

TimeObjective..

TotalTravelTime $=\mathrm{e}=\operatorname{sum}(\mathrm{j}, \mathrm{t}(\mathrm{j}) * \mathrm{x}(\mathrm{j}))$;

ConservationOfFlow(i)..

$\operatorname{sum}(\mathrm{j} \$(\mathrm{a}(\mathrm{i}, \mathrm{j})<>0), \mathrm{a}(\mathrm{i}, \mathrm{j}) * \mathrm{x}(\mathrm{j}))=\mathrm{e}=$ SingleTerminal $(\mathrm{i})$;

Capacity(j).

$\mathrm{x}(\mathrm{j})=\mathrm{l}=\operatorname{sum}(\mathrm{k} \$(\mathrm{DU}(\mathrm{j}, \mathrm{k})=1), \operatorname{LinkStatus}(\mathrm{k}))$;

option limrow $=0$

option limcol $=0$;

option solprint = off;

model MCSP " ... Practically ALL ... " / TimeObjective, ConservationOfFlow , Capacity /;

MCSP.reslim $=3600000$

MCSP.iterlim $=10000000$;

MCSP.sysout $=0$;

MCSP.optfile $=1$

AssemblyID.ap $=0$;

put AssemblyID ;

Put "Iteration, ODpair, TotalTravelTime, ModelStatus, CPUTime, Date, Time" / ; putclose ;

Paths.ap $=0$

put Paths ;

put "Iteration,ODPair,UndirLink" / ;

putclose ;

Warnings.ap $=0$;

put Warnings ;

put $" * * * * * * * * * * * * * * * * * * * * * * * * * * * * * * * * * * * * * * * * * * * * * * * * * * * * * * * * * * * * 1 /$

put "*** Start of Warning File for Iteration \#" RunID:0:0 " $\quad * * * "$ /;

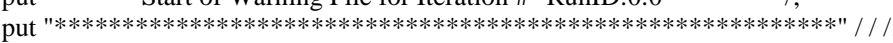

putclose;

RunID = RunID + 1;

NetSelectedLink $(k)=0$;

for (ResponderRouteIndex $=1$ to $\operatorname{card}(\mathrm{l})$ by 1 ,

WarningIndex $=$ WarningIndex +1 ;

SingleTerminal $(\mathrm{i})=\operatorname{sum}(\mathbf{l} \$(\operatorname{ord}(\mathrm{l})=$ ResponderRouteIndex $)$, Terminal $(\mathrm{l}, \mathrm{i}))$;

solve MCSP using LP minimizing TotalTravelTime;

RunIDfile.ap = 0;

put RunIDfile ;

put "RunID = " RunID:0:0 " ;" ;

putclose ;

AssemblyID.ap $=1$;

put AssemblyID

put RunID:0:0 ", " ResponderRouteIndex:0:0 ", " TotalTravelTime.l:0:3 ", " MCSP.solvestat:0:0 ", " MCSP.modelstat:0:0 ", " MCSP.resusd:0:2 ", " system.date ", " system.time /;

putclose ; 
* $\quad$ Check whether a feasible route exists

RouteFeasibilityIndexL=0\$(MCSP. modelstat=4)+1\$(MCSP. modelstat $<>4)$;

* If a feasible route does not exist then mention this in the warning file if(RouteFeasibilityIndexL=0,

LocalPath $(\mathrm{k})=0$;

NetSelectedLink $(\mathrm{k})=\max (\operatorname{LocalPath}(\mathrm{k})$, NetSelectedLink $(\mathrm{k}))$;

AssemblyID.ap = 1;

put AssemblyID

put RunID:0:0 ", " ResponderRouteIndex:0:0 ", " TotalTravelTime.l:0:3 ", " MCSP.modelstat:0:0 ", " MCSP.resusd:0:2 ", " system.date ", " system.time / ;

putclose ;

Warnings.ap $=1$

put Warnings ;

put WarningIndex:0:0 ".1 Routing of emergency responders for origin-destination pair \# " ResponderRouteIndex:0:0 ;

put "in the complete south-west Indiana road network is infeasible due to the unavailability of certain links." /;

putclose ;

)

* If a feasible route exists then mention this and include all links in the route. if(RouteFeasibilityIndexL=1,

LocalPath $(k)=\operatorname{sum}(j, D U(j, k) * x . l(j))$;

Paths.ap $=1$;

put Paths ;

loop( k\$(LocalPath(k)<>0) , put RunID:0:0 ", " ResponderRouteIndex:0:0 ", " k.tl:0:0 / );

putclose ;

NetSelectedLink(k) = max $(\operatorname{LocalPath}(\mathrm{k})$, NetSelectedLink(k));

* $\quad$ Check all links in the route have been verified

RouteVerificationIndexL $=\operatorname{prod}(\mathrm{k} \$(\operatorname{LocalPath}(\mathrm{k})=1), \operatorname{LinkVerification}(\mathrm{k}))$;

* $\quad$ Case that there are unverified links in the proposed shortest route

if( RouteVerificationIndexL $=0$,

Warnings.ap = 1 ;

put Warnings ;

put WarningIndex:0:0 ".1. The shortest route of emergency responders for origin-destination pair \# "

ResponderRouteIndex:0:0 " has not been verified in the " ;

put "complete south-west Indiana road network." ;

put / WarningIndex:0:0 ".2. For routing in the complete south-west Indiana road network the status of the following

links have to be verified:" / ;

$\operatorname{loop}(\mathrm{k} \$($ NetSelectedLink $(\mathrm{k})=1$ and LinkVerification $(\mathrm{k})=0)$,

put " "k.tl:0:0 ;

if(be(k)=1, put " (At least one bridge exists in this link)") ;

)

put / ;

* Case that there all links have been verified in the proposed shortest route

if ( RouteVerificationIndexL $=1$,

Warnings.ap = 1 ;

put Warnings ;

put WarningIndex:0:0 ".1. The shortest route of emergency responders for origin-destination pair \# "

ResponderRouteIndex:0:0 " has been verified in the " ;

put "complete south-west Indiana road network." /

) ;

) ; 
Warnings.ap $=1$;

put Warnings :

put / / /

put "*****

put "***

End of Warning File

$* * * " /$;

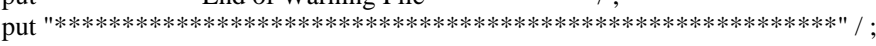

putclose ; 


\section{APPENDIX I: GAMS/CPLEX MANUAL}

The GAMS/CPLEX manual includes four sections. In Section I the installation of the GAMS/CPLEX software is described, along with the installation of the source code and the input files. In Section II, the input files are described and an indicative example is provided. In Section III, GAMS/CPLEX' execution is demonstrated, and finally in Section IV the format of the output files is described and an indicative example is provided. 
SECTION I: SETUP

In this section the latest version (1/31/2006) of the optimization software GAMS v22 is installed, the source code, the input and the output files are copied to the hard disk drive, and the GAMS IDE environment is calibrated.

STEP 1: $\quad$ Insert “Dynamic Rerouting” CD into the CD-ROM Drive.

STEP 2: Copy the "D: $\backslash$ Dynamic Rerouting” directory with all the files and subdirectories to c: $\backslash$. The directory “D: $\backslash$ Dynamic Rerouting” includes:

a) The GAMS executable file : “GAMS22-setup.exe”

b) The GAMS source code file: "DynamicRerouting.gms"

c) The input files “*.inc”.

d) The auxiliary file "RunIDfile.itm".

e) The GAMS/CLPEX options' file: “cplex.opt”

f) The output files “*.txt”.

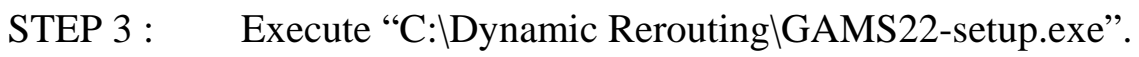

Screen 1: Close all other programs and click "next" to proceed with the installation.

Screen 2: Install to the default "C:IProgram Files\GAMS22.0" directory.

Screen 3: Accept the default option "Full installation" and click "next" to proceed with the installation. 
Screen 4: Accept the default option "GAMS" and click "next" to proceed with the installation.

Screen 5: Accept the default option “Create a Desktop Icon” and click "next” to proceed with the installation.

Screen 6: Click "Install” to finalize the installation. GAMS is now being installed with the options previously selected.

Screen 7: $\quad$ The following dialog box appears: "Do you want to copy an existing license file?”. The current version of GAMS allows modeling of any instance of the "Dynamic Rerouting” problem and solves only small instances of it. In order to solve large instances the appropriate license file should be acquired from www.gams.com. The installation can continue by selecting "No". GAMS is now installed with full modeling and debugging capabilities, and the license file to solve small instances of the "Dynamic Rerouting” problem.

Screen 8: Click "Finish" to complete the installation and launch GAMS IDE. GAMS IDE is now launched.

STEP 4: In the GAMS IDE environment, go to FilelOptions and then Options $\backslash$ Execute. Check "Use following additional parameters". In the following input box insert “idir "C:IDynamic Rerouting"”, and click OK to save the inserted options. 
STEP 5: In the GAMS IDE environment, go to FilelOptions and then Options Solvers. Check all the options associated with CPLEX. All options should now appear checked with an " $X$ " sign instead of the previous “.” sign. 


\section{SECTION II: INPUT FILES}

In this section the functionality and the structure of the input files are described. All *.inc input files are editable with a text editor like "notepad". The INDOT administered network is used as the input network and routing is performed among major population centers.

Input file name

Terminal.inc:

ArcNodeIncidence.inc: The information indicating the topology of the studied network. For instance, record “a("6","5")=1; a("1","5")=1;” indicates that link 5 originates from node 6 and ends to node 1 . This file is part of the static database.

DirectUndirected.inc: $\quad$ The information indicating the relation between a directed and an undirected link. For instance, record “DU("310","1")=1;” indicates that the directed link 310 comes from the undirected link 1 . This file is part of the static database. 
BridgeExists.inc:

LinkStatus.inc:

LinkVerification.inc:
The information indicating whether a bridge exists in an undirected link. For instance, record "be("18")=1;" indicates that there is a bridge in undirected link 18. This file is part of the static database.

The information indicating the availability status of an undirected link. For instance, record "LinkStatus("10")=1;” indicates that undirected link 10 is available. This file is part of the dynamic database.

The information indicating whether the availability status of an undirected link has been verified. For instance, record "LinkVerification("10")=0;" indicates that the availability status of undirected link 10 has not been verified. This file is part of the dynamic database. 
SECTION III: EXECUTION

In this section the an instance of the "Dynamic Rerouting” problem is solved. It is noted that there is no reason to edit the source code because all the input parameters are inserted through the input files. In order to solve the "Dynamic Rerouting” problem, it is needed to:

1. Insert the problem parameters in the input files, as previously described, with the use of text editor like "notepad".

2. Load GAMSIDE (with the GAMS/CPLEX license files installed).

3. Go to File\Open and select the source code file "C: $\backslash$ Dynamic Rerouting $\backslash$ DynamicRerouting.gms”.

4. Select File\Run to execute the code. 


\section{SECTION IV: OUTPUT FILES}

In this section IV the output files of the "Dynamic Rerouting” problem's solution are described. They are in the form of text file *.txt format. This format is editable from a text editor like “notepad”.

Output file name

Description and example

OutAssemblyIDDR.txt: Key characteristics of the solved instance of the "Dynamic Rerouting” problem. From left to right, it includes:

1. The serial number of the "Dynamic Rerouting" instance solved. It is strictly an increasing natural number, which is used as the unique ID of the instance.

2. The route ID.

3. The total travel time for that route in minutes.

4. Model status, which is 1 if optimality is achieved.

5. The CPU computational time in CPU seconds.

6. The date of execution.

7. The time of execution.

OutWarningsDR.txt: This file indicates to the controller which routes have undirected links whose availability status have not been verified. These undirected links are listed. Next to the link ID, the existence of a bridge in that link is indicated. 
OutPathsDR.txt:

This file includes the undirected links used in the optimal dynamic routes. From left to right, it includes:

1. The “Dynamic Rerouting” instance's serial number. It is a strictly increasing natural number which is used as the unique ID of the specific “Dynamic Rerouting” problem solved.

2. The route ID.

3. The included undirected links. 